\title{
Assimilation of Satellite Soil Moisture for Improved Atmospheric Reanalyses
}

\author{
CLARA DRAPER \\ Cooperative Institute for Research in Environmental Sciences, University of Colorado Boulder, \\ and Physical Sciences Division, NOAA/Earth System Research Laboratory, Boulder, Colorado \\ ROLF H. REICHLE \\ Global Modeling and Assimilation Office, NASA Goddard Space Flight Center, Greenbelt, Maryland
}

(Manuscript received 7 November 2018, in final form 15 February 2019)

\begin{abstract}
A newly developed, weakly coupled land and atmosphere data assimilation system for NASA's Global Earth Observing System model is presented, and used to demonstrate the benefit of assimilating satellite soil moisture into an atmospheric reanalysis. Specifically, Advanced Scatterometer and Soil Moisture Ocean Salinity soil moisture retrievals are assimilated into a system that uses the same model, atmospheric assimilation system, and atmospheric observations as the Modern-Era Retrospective Analysis for Research and Applications, version 2 (MERRA-2). The atmosphere is sensitive to soil moisture only under certain conditions. Hence, while the globally averaged model improvements were small, regionally, the soil moisture assimilation induced some substantial improvements. For example, in a large region spanning from western Europe across southern Russia, the soil moisture assimilation decreased the RMSE against independent station observations of daily maximum $2-\mathrm{m}$ temperature $\left(T_{\max }^{2 \mathrm{~m}}\right)$ by up to $0.4 \mathrm{~K}$, and of $2-\mathrm{m}$ specific humidity $\left(q^{2 \mathrm{~m}}\right)$ by up to $0.5 \mathrm{~g} \mathrm{~kg}^{-1}$. Over all available stations, the mean $T_{\max }^{2 \mathrm{~m}}$ RMSE was reduced from 2.82 to $2.79 \mathrm{~K}$, while the mean $q^{2 \mathrm{~m}}$ RMSE was reduced from 1.25 to $1.20 \mathrm{~g} \mathrm{~kg}^{-1}$. The soil moisture assimilation also reduced the mean RMSE across 29 flux tower sites from 34.2 to $32.6 \mathrm{~W} \mathrm{~m}^{-2}$ for latent heating, and from 37.7 to $36.5 \mathrm{~W} \mathrm{~m}^{-2}$ for sensible heating. For all variables evaluated, the soil moisture assimilation improved the model at monthly to seasonal, rather than daily, time scales. Based on the above experiments, it is recommended that satellite soil moisture be assimilated into future reanalyses, including the follow-on to MERRA-2.
\end{abstract}

\section{Introduction}

By limiting the amount of water available to plants for evapotranspiration, soil moisture can control the partitioning of incoming radiation at the land surface into latent heating (or evapotranspiration) and sensible heating. Consequently, soil moisture can have a profound impact on the evolution of the boundary layer, particularly during the warm seasons when incoming radiation and evapotranspiration are largest (Betts 2009). Soil moisture anomalies typically persist much longer than atmospheric anomalies, giving anomaly decay time scales of around 1-3 months (Vinnikov et al. 1996; Entin et al. 2000). These relatively long decay time scales enhance the impact of soil moisture on the atmosphere, and various studies have shown that the soil moisture initialization in weather and climate

\footnotetext{
Corresponding author: Clara Draper, clara.draper@noaa.gov
}

models can improve forecast skill across a range of time scales. For example, such improvements have been reported in forecasts of days 1-3 (Dirmeyer and Halder 2016) and days 1-9 (Drusch and Viterbo 2007), as well as in subseasonal to seasonal forecasts of 45 days (Koster et al. 2010) and 56 days (van den Hurk et al. 2012).

Despite the importance of soil moisture to the atmosphere, the model soil moisture in NASA's current Modern-Era Retrospective Analysis for Research and Applications, version 2 (MERRA-2; Gelaro et al. 2017) is not directly constrained with observations. The aim of this study is then to develop a land data assimilation system for potential use in NASA's future reanalyses, and to test whether such a land data assimilation can improve the modeled soil moisture and atmospheric states in NASA's future reanalyses. The focus is on improving both the land and the atmosphere, since NASA's next reanalysis will be an integrated Earth 
system reanalysis. In the current study, we have coupled an ensemble Kalman filter (EnKF) for land data assimilation to the MERRA-2 atmospheric data assimilation system. We have then used the coupled land-atmosphere data assimilation to test the impact of assimilating Advanced Scatterometer (ASCAT) and Soil Moisture Ocean Salinity (SMOS) soil moisture retrievals into a system that uses the same model, atmospheric assimilation, and suite of atmospheric observations as MERRA-2. Below, the current state of land data assimilation within the context of atmospheric modeling is briefly reviewed, to place the current study in context, and to justify the chosen land data assimilation design and approach.

Currently, there are two main data assimilation approaches used to constrain model soil moisture in atmospheric modeling and assimilation systems. The first approach, used by most NWP centers outside the United States, as well as in NOAA's regional Rapid Refresh system, is to constrain model soil moisture (and soil and surface temperatures) with observations of air temperature and relative humidity at the 2-m screen-level height (Mahfouf 1991; Hess 2001; Bélair et al. 2003; Rodriguez et al. 2003; Dharssi et al. 2011; de Rosnay et al. 2013; Benjamin et al. 2016). The idea behind assimilating the 2-m observations is (i) if the modeled land surface is too warm and dry, then latent heating will be underestimated and the sensible heating will be overestimated, leading to underestimated $2-\mathrm{m}$ relative humidity and overestimated 2-m temperatures; and (ii) these forecast errors can be reduced by adjusting the initial soil states accordingly.

The screen-level observations are most often assimilated at NWP centers using a simplified extended Kalman filter (EKF) or optimal interpolation, although Environment Canada is using an EnKF in their highresolution regional system (Milbrandt et al. 2016). In each case, the land data assimilation is "weakly coupled" to the atmospheric assimilation, in that the land and atmospheric data assimilation are performed in parallel, and do not directly share information (i.e., observations or error covariances), except via their influence on the subsequent forecast cycles. Since the land surface models used in NWP systems simulate each grid cell independently from its neighbors, the land assimilation is also performed independently at each model grid cell (i.e., horizontal error correlations are neglected). While assimilating screen-level observations has been shown to improve near-surface forecasts, in many cases this is achieved while degrading the modeled soil moisture (Hess 2001; Drusch and Viterbo 2007; Draper et al.2011; Carrera et al.2019), which is effectively tuned to compensate for errors elsewhere in the model (e.g., in the radiation or surface physics).
The second approach is to assimilate satellite observations of near-surface soil moisture. This is the approach being tested in this study, since it avoids the potential negative impact on model soil moisture of assimilating the screen-level observations, and also takes advantage of the near-global coverage of the relevant satellites. Within the NWP community, the Met Office and ECMWF assimilate ASCAT near-surface surface soil moisture, in addition to the screen-level observations discussed above (Dharssi et al. 2011; de Rosnay et al. 2013; Candy et al. 2017). In both cases, the ASCAT observations are assimilated using the same simplified EKF used to assimilate screen-level observations. A major difficulty of assimilating satellite soil moisture is that the observations relate only to a near-surface $(1-5 \mathrm{~cm})$ layer, while it is the much deeper (surface to $0.5-1.0 \mathrm{~m}$ ) root-zone soil moisture that exerts the most control over evapotranspiration. At ECMWF, the increments in the deeper soil moisture layers from assimilating the satellite soil moisture are small (much smaller than the increments from assimilating the screen-level observations), and the ASCAT assimilation has a neutral impact on the model root-zone soil moisture skill (de Rosnay et al. 2013). Evaluation statistics have not been published for the current Met Office soil moisture assimilation scheme, although an earlier version (by design) had a very limited impact on the root-zone soil moisture (Dharssi et al. 2011). ECMWF's ERA-5 (Hersbach and Dee 2016), currently in production, will be the first global atmospheric reanalysis to assimilate satellite soil moisture information. Specifically, soil moisture retrievals from ASCAT and its predecessors are being assimilated with the simplified EKF, again alongside the screen-level observations (J. Muñoz-Sabater 2018, personal communication).

Satellite soil moisture assimilation is also being pursued by the hydrology community, using offline (i.e., stand-alone) land surface models (LSMs). The hydrology community generally favors the EnKF over the EKF-type approaches used at NWP centers because the EnKF is much more flexible, while also being somewhat less vulnerable to the strong nonlinearities of land surface models. Using offline LSMs, the EnKF assimilation of near-surface soil moisture has been shown to improve simulated near-surface and root-zone soil moisture temporal anomalies (Draper et al. 2012; De Lannoy and Reichle 2016) and simulated latent heating (Peters-Lidard et al. 2011).

Comparisons of the EKF and EnKF assimilation of soil moisture suggest that their performance is very similar, with the EnKF producing slightly better results (Reichle et al. 2002; Muñoz Sabater et al. 2007; Fairbairn et al. 2015). Most NWP centers are using the simplified EKF-type approaches as they are computationally cheaper. The major computational cost for both schemes 
is associated with the additional forecast model integrations required. For the simplified EKF, the tangent linear of the forecast model is required, necessitating an additional forward integration over each assimilation cycle for each state variable in the update vector (e.g., four total integrations for a three-state soil moisture vector). For the EnKF, the number of additional forward integrations is determined by the ensemble size. However, the land surface does not experience chaotic error growth, and relatively small ensemble sizes of 20-30 are generally considered sufficient (Peters-Lidard et al. 2011; Carrera et al. 2015; De Lannoy and Reichle 2016).

An EnKF was chosen for NASA's land data assimilation scheme, as it offers greater flexibility for future development. In particular, additional variables can be easily added to the state vector, the description of the model errors is more intuitive and flexible, and crosscorrelated background errors (between different state variables, and/or across space) can be accounted for. Several of the EKF-based land data assimilation systems used in NWP (Bélair et al. 2003; Rodriguez et al. 2003; Dharssi et al. 2011) use an offline LSM for the additional model integrations required by the EKF. The same approach is used here for the EnKF, in that the ensemble of land surface states required by the EnKF are produced using an ensemble of offline LSM integrations, forced by atmospheric fields from the most recent atmospheric assimilation cycle.

The above two approaches both directly update the modeled soil moisture states with observations through data assimilation. Another, less direct, approach to introducing observed information into the modeled soil moisture is to correct the model-generated precipitation with observations. In both the MERRA-2 and Climate Forecast System, version 2 (Saha et al. 2014), reanalyses, the model-generated precipitation is corrected toward observations immediately before entering the land surface (Saha et al. 2010; Reichle et al. 2017b). Precipitation is the main driver of soil moisture dynamics, and as would then be expected, correcting the precipitation with observations in MERRA-2 improves the model soil moisture (Reichle et al. 2017a), with strong evidence that this in turn improved the simulated surface fluxes and daily maximum 2-m temperatures $\left(T_{\max }^{2 \mathrm{~m}}\right.$; Draper et al. 2018). While the use of observed precipitation clearly improves modeled soil moisture, this approach is limited in that it addresses only precipitation-related soil moisture errors. It also relies on high quality daily precipitation observations, which are not available in many regions. In particular, Africa, South America, and the tropics have sparse rain gauge networks. Since it is clearly beneficial, the use of the precipitation corrections has been retained in the current study.

\section{Methods and data}

\section{a. Experiment outline}

Two pairs of assimilation experiments were performed to test the benefit of assimilating the satellite soil moisture observations, as outlined in Table 1. The first and main pair of experiments was designed to test the impact of assimilating satellite soil moisture observations into the Goddard Earth Observing System (GEOS) atmospheric general circulation model (AGCM). In the control AGCM assimilation experiment (AGCMDAatmos) the AGCM, atmospheric data assimilation system, and atmospheric observations were identical to those used in MERRA-2, including the use of observation-corrected precipitation at the land surface and the aerosol analysis. The second AGCM assimilation experiment (AGCM-DAland/atmos) was the same as AGCM-DAatmos, except that the ASCAT and SMOS near-surface soil moisture retrievals were also assimilated into the land component of the AGCM. The AGCM assimilation experiments covered 1 April31 August 2013, with the first two weeks excluded from the evaluation against independent observations to allow for assimilation spinup.

As will be discussed in section $2 \mathrm{c}$, evaluation of modeled soil moisture is difficult and generally restricted to assessing temporal anomalies, and hence requires long time series. To better examine how the soil moisture assimilation affects the model soil moisture, a second pair of experiments was then conducted over a much longer time period, in which the soil moisture observations were assimilated into an offline (stand-alone) copy of the LSM used in the GEOS AGCM. For these experiments, the GEOS LSM, Catchment (Koster et al. 2000), was driven with surface meteorological forcing data from MERRA-2, using the same model settings and parameters as in MERRA-2. In the control LSM experiment (LSMopenloop) no land data assimilation was performed. In the second LSM experiment (LSM-DAland), ASCAT and SMOS near-surface soil moisture retrievals were assimilated. The LSM experiments were run from June 2010 to December 2016, the maximum period for which both ASCAT and SMOS soil moisture retrievals were available when these experiments were conducted.

\section{b. The data assimilation systems}

\section{1) AtMospheric DAtA ASSIMILAtion}

The atmospheric data assimilation system used in the AGCM assimilation experiments is the GEOS, version 5.12.4, system as was used in MERRA-2. This system 
consists of the GEOS AGCM (Rienecker et al. 2008; Molod et al. 2015) and the GSI 3D-Var analysis scheme (Wu et al. 2002; Kleist et al. 2009), with the latter used to assimilate the observations listed in Table 2 of Gelaro et al. (2017). For the GEOS 3D-Var, each 6-h assimilation cycle consists of three steps, as shown in the top portion of Fig. 1. First is the predictor segment, which is an AGCM forecast (with no assimilation) across the 6-h assimilation window, producing the first-guess model background. Second is the atmospheric analysis, in which the background is compared to the observations, and the assimilation increment is calculated. Third is the corrector segment, during which the model is rewound, and the 6-h forecast across the assimilation window is repeated, with the assimilation update added incrementally at each forecast step (Bloom et al. 1996), such that the full increment calculated in step 2 has been added by the end of the forecast.

These experiments also used the MERRA-2 precipitation correction scheme, in which the model-generated precipitation is corrected toward observations before entering the land surface (Reichle et al. 2017b). In this scheme, the precipitation corrections are tapered toward the poles because of increased uncertainty in the observations at high latitudes. Equatorward of $42.5^{\circ}$, the model-generated precipitation is fully corrected to the observations, while poleward of $62.5^{\circ}$, the modelgenerated precipitation is retained as is, and between these two latitudes the weighting applied to the observations is linearly tapered between the two extremes (these two latitude bands will be indicated on all relevant maps of the results). As in MERRA-2, the AGCM was run using a cubed-sphere horizontal grid at approximately $0.5^{\circ}$ resolution, with 72 hybrid-eta levels from the surface to $0.01 \mathrm{hPa}$, the data assimilation was performed on a $0.5^{\circ}$ by $0.625^{\circ}$ latitude-longitude grid, and the model output files were produced on the same latitude-longitude grid.

\section{2) LAND DATA ASSIMILATION}

For both experiments with land assimilation, AGCMDAland/atmos and LSM-DAland, the GEOS land EnKF (De Lannoy and Reichle 2016; Reichle et al. 2017c) was used to assimilate the soil moisture observations. This is a stochastic EnKF, and was run here in "1D" mode, in which all horizontal error correlations are neglected, using a 3-h assimilation cycle and 20 ensemble members. Only a single realization of the land-atmosphere system is available from MERRA-2 (or from the MERRA-2 like system used for the AGCMDAland/atmos experiment), and following standard practice in offline land DA, the ensemble of land states for the EnKF was created by randomly perturbing the 


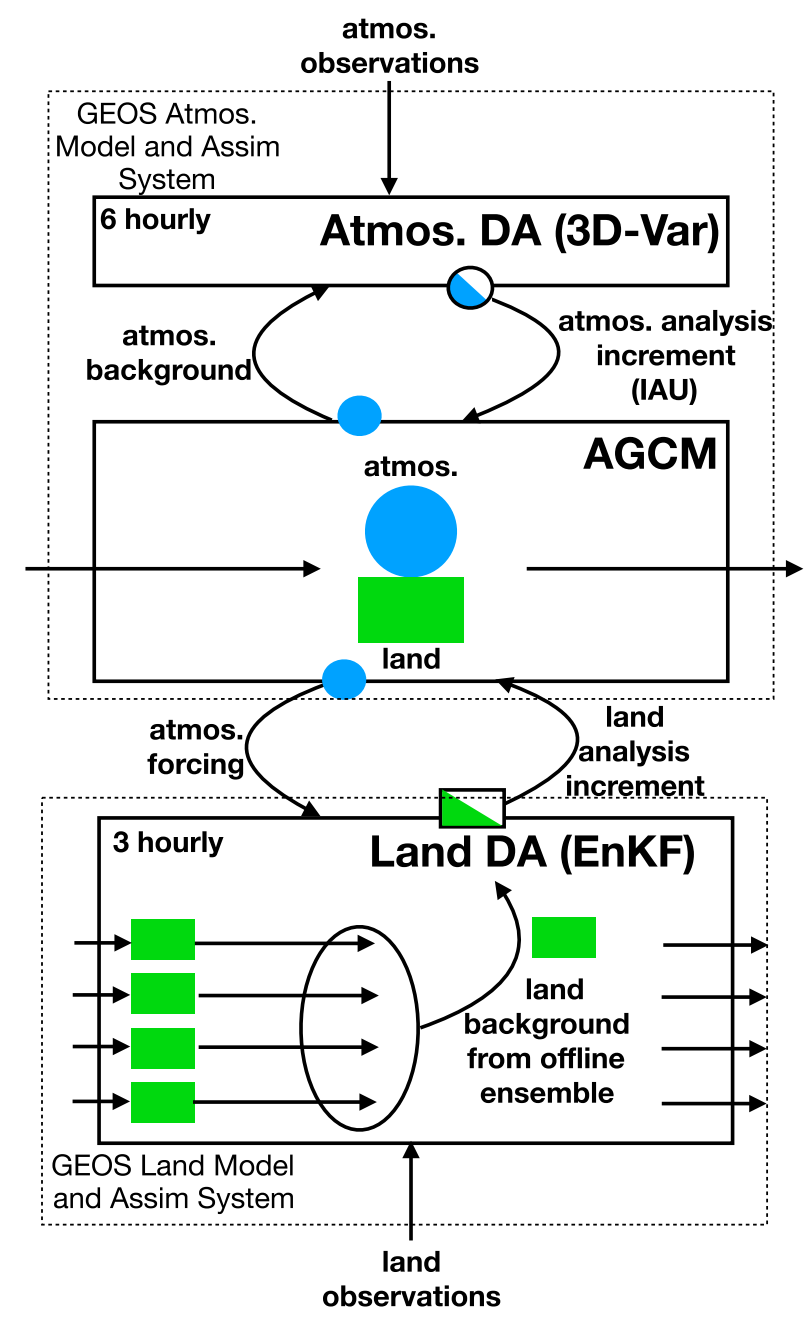

FIG. 1. Schematic of the GEOS weakly coupled land-atmosphere data assimilation system, showing the coupling of the GEOS EnKF for land assimilation to the GEOS 3D-Var for atmospheric assimilation.

atmospheric forcing and land state variables, using the same perturbation settings as in Liu et al. (2011). The model and assimilation were performed on the same approximately $0.5^{\circ}$ cubed-sphere grid used for the AGCM in MERRA-2, and the output was written on the same $0.5^{\circ}$ by $0.625^{\circ}$ latitude-longitude grid used for MERRA-2 output.

\section{3) Coupled land AND ATMOSPHERE DATA ASSIMILATION}

The coupled land-atmosphere data assimilation experiment, AGCM-DAland/atmos, was run in weakly coupled mode as outlined in Fig. 1. During each predictor segment of the atmospheric assimilation, the surface meteorological forcing fields needed to drive the land model are output and then used to force the ensemble of LSMs, which provide the background firstguess ensemble for the land EnKF. The land increments produced by the EnKF are applied to the land surface model ensemble members in the usual manner, and then also applied to the land surface model within the AGCM during the corrector segment. Following initial testing, the full land increment is added to the AGCM at the nominal observation time (i.e., at the midpoint of each 3-h land DA window), rather than using the incremental approach of the atmospheric updates.

\section{4) AsSimilated SOIL MOISTURE OBSERVATIONS}

Following Draper et al. (2012), soil moisture retrievals from both active and passive sensors have been assimilated, in this case from the C-band active ASCAT, and the L-band passive SMOS instruments, respectively. The assimilated ASCAT observations were version WARP5.6.5, provided by the Vienna University of Technology as time series files (Wagner et al. 1999; Naeimi et al. 2009). The soil moisture observations are retrieved from the ASCAT instruments on the MetOp-A and $\mathrm{Met} O p-B$ satellites, and have a resolution of approximately $25 \mathrm{~km}$, but are reported on an oversampled $12.5-\mathrm{km}$ discrete global grid (DGG). Strictly speaking, the retrieved variable for the ASCAT dataset is a percentile degree of surface saturation (which must be scaled by local porosity to obtain a volumetric soil moisture), but we refer to it here as a "soil moisture" for convenience. The processing and quality control applied to the ASCAT observations were the same as in Draper et al. (2012), except that the land-cover dataset used to identify and screen regions of dense vegetation has been updated to the Global Land Cover Characteristics database, version 2.0 (USGS 2000), as was used in MERRA-2. Based on this dataset, the ASCAT soil moisture retrievals for locations identified as broadleaf evergreen were excluded from the assimilation. The assimilated SMOS soil moisture retrievals were extracted from the Soil Moisture Level 2 User Data Product (SMUDP2), version 552, on a $15-\mathrm{km}$ DGG grid, and are the same data (extended to include 2016) that were assimilated by De Lannoy and Reichle (2016).

The ASCAT and SMOS observations were regridded onto the MERRA-2 output grid before being assimilated, by assigning the average of all observations that fall within each MERRA-2 grid cell to all land model tiles within that cell. Figure 2 shows the number of soil moisture observations assimilated in the 5-month AGCM-DAland/atmos experiment. ASCAT observation were assimilated over $66 \%$ of the global land area, with only regions of dense vegetation in the tropics and Pacific Northwest, as well as a region surrounding the Himalayas, having no observations. By contrast, the 

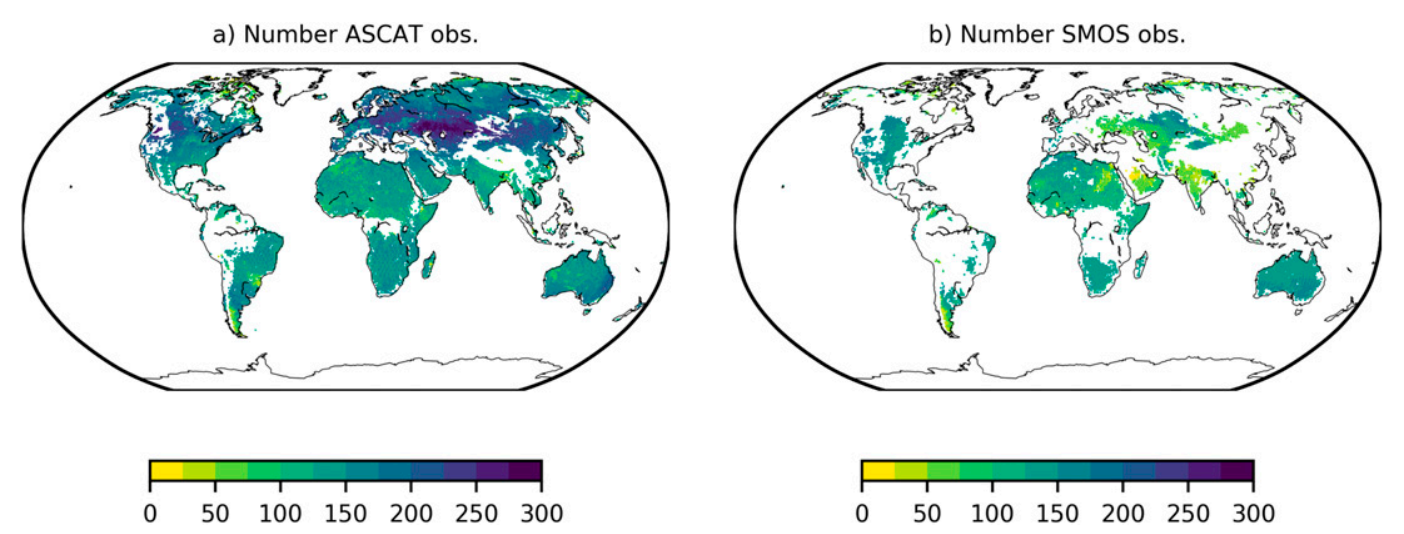

FIG. 2. Number of soil moisture observations assimilated in the 153 day AGCM-DAland/atmos experiment for (a) ASCAT and (b) SMOS.

SMOS observations were assimilated over only $31 \%$ of the global land area. The greater coverage for ASCAT is due to there being two ASCAT instruments in orbit (on $M e t O p-A$ and $M e t O p-B$ ), and also due to differences in the quality control applied to each. In particular, the SMOS observations must be screened to remove radio frequency interference contamination (Oliva et al. 2012), which is much less problematic for ASCAT. Also, while there is no evidence that ASCAT has higher relative skill than SMOS over dense vegetation, the screening for dense vegetation applied to SMOS by De Lannoy and Reichle (2016) was more stringent than that applied to ASCAT by Draper et al. (2012).

Large biases are ubiquitous between observed and modeled soil moisture (Reichle et al. 2004). Since there is no established soil moisture truth against which to anchor these biases, it is standard practice (PetersLidard et al. 2011; Draper et al. 2012; de Rosnay et al. 2013; Fairbairn et al. 2015) when assimilating satellite soil moisture observations to "bias correct" those observations prior to assimilation by rescaling them to locally match the model climatology (i.e., the mean, variance, and possibly higher-order moments; Reichle and Koster 2004). This rescaling removes the local systematic differences between the modeled and observed near-surface soil moisture, allowing the assimilation to ingest unbiased information in the form of temporal anomalies.

In these experiments, the bias correction was trained on the maximum available time period, from June 2010 to December 2016. Specifically, for both experiments in which soil moisture was assimilated (LSM-DAland and AGCM-DAland/atmos), the assimilated soil moisture observations were rescaled to match the cumulative distribution function (CDF) of the ensemble-mean of the LSM-openloop experiment, following Reichle and Koster (2004).
In past soil moisture assimilation experiments with the GEOS EnKF, including Draper et al. (2012) and De Lannoy and Reichle (2016), the observation error standard deviation has been specified as a global constant in the observation climatology. While a preliminary study concluded that using a more realistic spatial and/or temporal observation error distribution does not improve the assimilation outcome (Draper and Reichle 2018), we have nonetheless adopted a more realistic approach here. Specifically, the observation error standard deviation was specified as a fraction of the local (grid cell) observation time series standard deviation, using a fraction of 0.6 for both ASCAT and SMOS. This value was chosen to give global observation error standard deviation distributions with median values (and also first and third quartiles) very close to that used in Draper et al. (2012) and De Lannoy and Reichle (2016).

\section{c. Evaluation data and metrics}

For the LSM experiments, the impact on the model soil moisture of assimilating the satellite soil moisture has been evaluated by comparing the ensemble mean from each experiment against in situ observations hosted by the International Soil Moisture Network (ISMN; Dorigo et al. 2011). For the AGCM assimilation experiments the impact of assimilating the satellite soil moisture observations has been evaluated by comparing the AGCM output land surface fluxes, $T_{\max }^{2 \mathrm{~m}}$, and 2-m specific humidity $\left(q^{2 \mathrm{~m}}\right)$ to independent observations from the FLUXNET2015 (Fluxnet 2015), Global Historical Climatology Network (GHCN) (Menne et al. 2012a,b), and Hadley Centre Integrated Surface Database (HadISD; Smith et al. 2011; Dunn et al. 2016) datasets, respectively. The method used to process and quality control each of these datasets is detailed in the appendix, and the resulting observation coverage is 
shown in Fig. 3. In total, 215 (199) ISMN sites were used to evaluate the near-surface (root zone) soil moisture, most of which are in the United States (Fig. 3a). For the surface latent and sensible heat fluxes, 29 sites were used, 18 of which are in the Northern Hemisphere with the other 11 being in Australia (Fig. 3b). The GHCN $T_{\max }^{2 \mathrm{~m}}$ and HadISD $q^{2 \mathrm{~m}}$ datasets are much more extensive than ISMN and FLUXNET2015, although still far from global. Figures $3 \mathrm{c}$ and $3 \mathrm{~d}$ show the station density, in terms of the number of stations contributing to the gridcell average on a representative day (following the processing of the station observations onto the MERRA-2 grid, as described in the appendix). In these figures, just $12 \%$ of the MERRA- 2 grid cells are observed by GHCN, while $8 \%$ are observed by HadISD. These two datasets are based on observations from many of the same stations, giving similar global coverage, with few observations over Africa, South America, and much of Asia.

Comparing modeled and observed soil moisture estimates is difficult. The soil moisture variable defined by a given model is specific to the physics of that model, and will not generally match the definition of an observed soil moisture (Koster et al. 2009). There are also significant representativity differences associated with the differing spatial resolutions of point-based in situ observations and model grid-scale estimates. Hence, observations from individual in situ sensors are best used to evaluate only the temporal behavior of the model. Here, we measured the agreement between the LSM experiments and in situ observations using anomaly correlations. Unless otherwise stated, the anomaly correlation $R_{\text {anom }}$ has been calculated using anomalies from the mean seasonal cycle, with the mean seasonal cycle estimated for a given day as the mean of the 31-day window surrounding that day of year, using data from all years in the time series.

In experiments assimilating satellite soil moisture into the Catchment LSM, Draper and Reichle (2015) found that the model surface soil moisture skill gained from the assimilation was split between improved subseasonal anomalies (e.g., detection of surface wetting associated with an individual rain event) and improved interannual anomalies (e.g., detection of an unusually wet spring in a given year). Here, we again wish to evaluate the impact of our soil moisture assimilation at different time scales, however, the high quality grid-scale in situ observations used for evaluation by Draper and Reichle (2015) are available at only a few sites, and not for root-zone soil moisture over long time scales. We have instead relied on indirectly evaluating the different time scales, by testing how the anomaly correlations depend on the method used to estimate the anomalies. By calculating anomalies
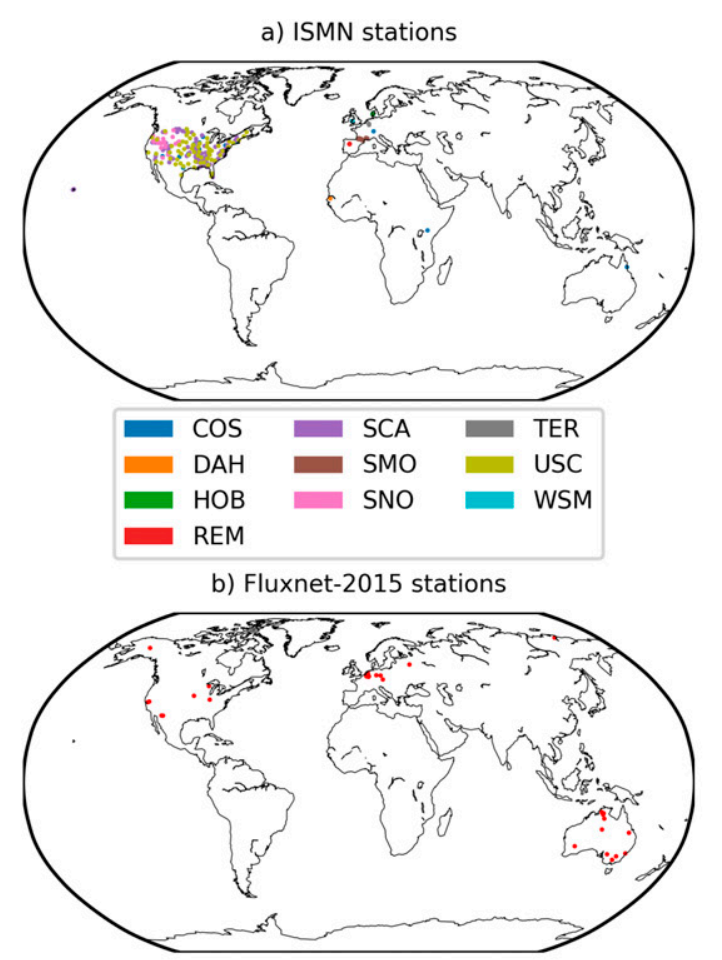

c) GHCN station density
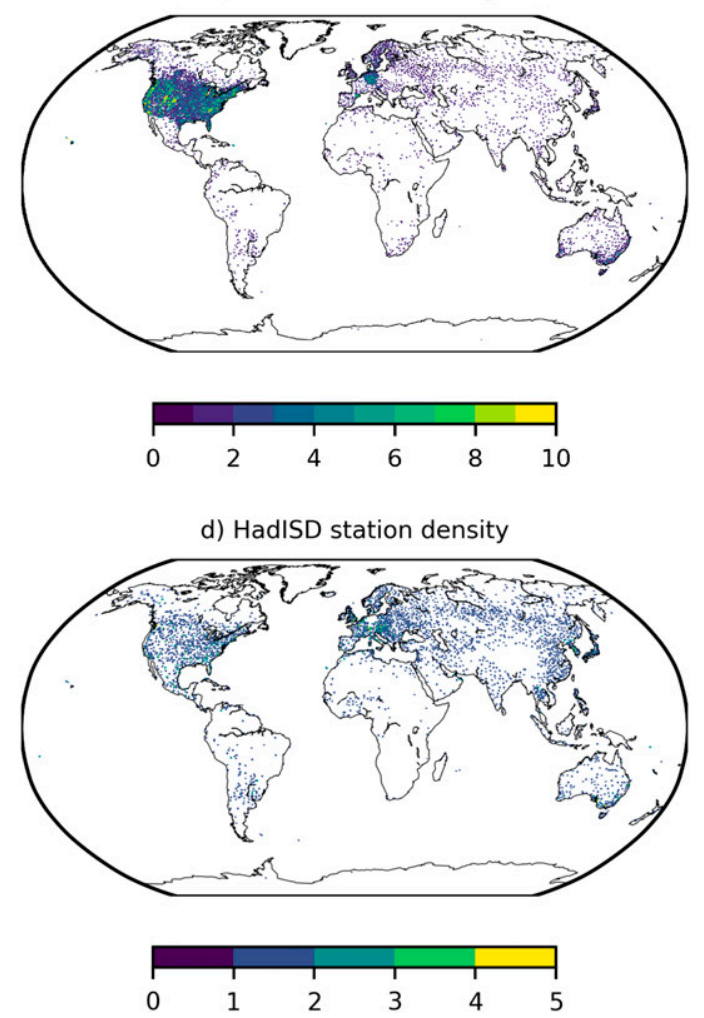

FIG. 3. Locations of the (a) ISMN in situ soil moisture stations (legend refers to the first three letters of each network, as listed in Table A2) and (b) FLUXNET2015 stations used in this study, and density (stations per grid cell) on 1 Jun 2013 of the (c) GHCN $T_{\max }^{2 \mathrm{~m}}$ and (d) HadISD $q^{2 \mathrm{~m}}$ stations. 
a) Ranom surface SM

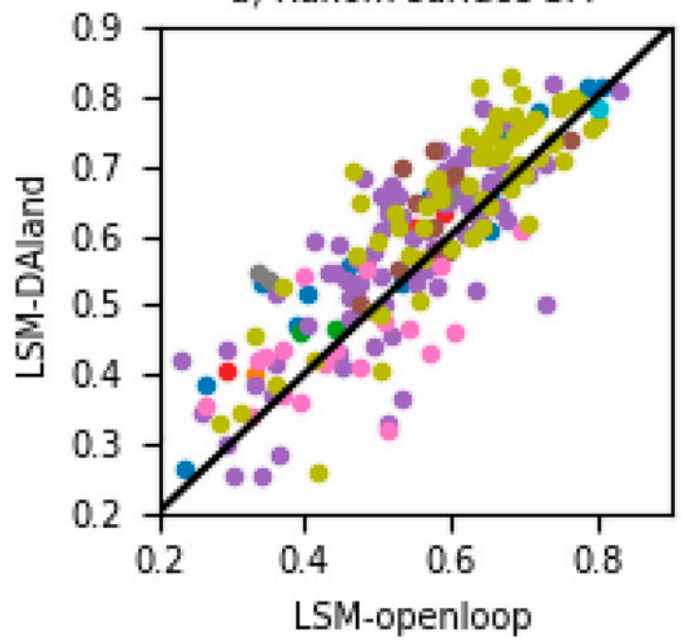

b) Ranom root-zone $5 \mathrm{M}$

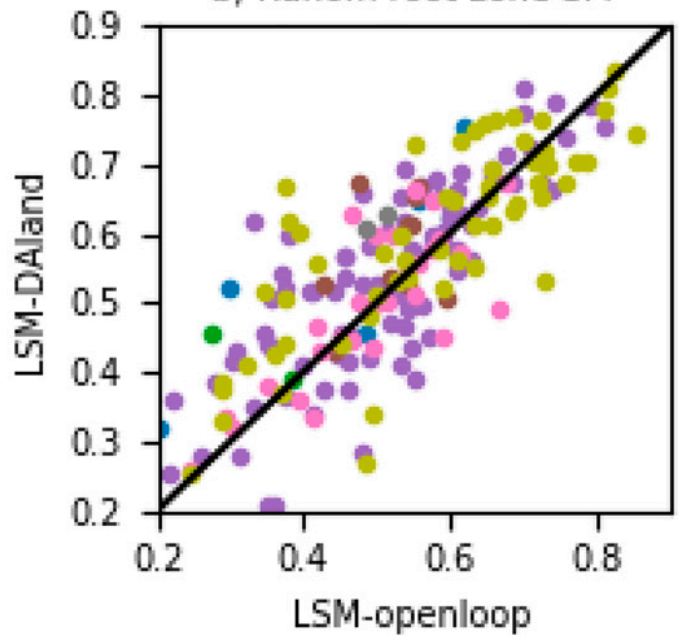

FIG. 4. Scatterplots for LSM-DAland vs LSM-openloop $R_{\text {anom }}$ for the (a) surface, and (b) root-zone soil moisture. Colors indicate the networks, as indicated in Fig. $3 \mathrm{a}$.

from the mean seasonal cycle, the $R_{\text {anom }}$ metric presented above is sensitive to both short-lived subseasonal anomalies and longer-lived interannual anomalies. We have also estimated the anomaly correlation using anomalies with respect to a simple 31-day moving average. This metric, denoted as $R_{\text {anom:subseas, }}$ measures only the skill in estimating subseasonal anomalies.

When comparing the evaluation metrics across experiments, the significance of the difference in each metric has been tested using two-sided tests, at a $10 \%$ significance level. For the root-mean-square error (RMSE) and the unbiased RMSE (ubRMSE, or error standard deviation), the significance was tested using a paired bootstrap test with 10000 replicates. For the $R_{\text {anom }}$, the significance was tested using a Fisher $Z$ transform, while for biases the significance was tested using a 2-sample $t$ test. In all cases, except the bootstrap, an effective sample size was used to account for serial autocorrelation in the time series being compared, following the method of Draper et al. (2012). Finally, for comparisons to the sparse observation networks (i.e., ISMN soil moisture and FLUXNET2015 fluxes), the significance of the mean differences between the statistics across multiple sites has been estimated from the results at each site after accounting for dependence between closely located sites, following the method of Draper et al. (2013). On the other hand, for the denser observation networks (GHCN $T_{\max }^{2 \mathrm{~m}}$ and HadISD $q^{2 \mathrm{~m}}$ ) for which maps of gridded statistics have been produced, we do not perform significance tests on the global mean of each statistic because of the difficulty of accounting for the spatial correlations in densely sampled gridded statistics.

\section{Results and discussion}

\section{a. The LSM experiments}

Scatterplots of the $R_{\text {anom }}$ between the ISMN in situ observations and the daily average ensemble mean soil moisture from the LSM experiments confirm that assimilating the satellite soil moisture slightly improved the model soil moisture (Fig. 4). For the near-surface soil moisture, the mean $R_{\text {anom }}$ over all sites was slightly increased from 0.54 for the LSM-openloop experiment to 0.58 for the LSM-DAland experiment, with the soil moisture assimilation increasing the $R_{\mathrm{anom}}$ at $60 \%$ of the sites. Likewise, for the root-zone soil moisture, the mean $R_{\text {anom }}$ across all sites was slightly increased from 0.51 for LSM-openloop to 0.54 for LSM-DAland, with the assimilation again increasing the $R_{\text {anom }}$ at $60 \%$ of the sites. While small, the increase in the mean $R_{\text {anom }}$ for both soil layers was statistically significant. These small improvements are also consistent with other studies assimilating soil moisture retrievals into a land surface model forced by observed precipitation (De Lannoy and Reichle 2016; Carrera et al. 2019).

Recall from section 2c that the $R_{\text {anom }}$ metric shown in Fig. 4 measures anomalies at both subseasonal and interannual time scales, and that if the anomalies are instead calculated using a 31-day moving average, the resulting anomaly correlation, $R_{\text {anom:subseas }}$, reflects only skill in the estimation of subseasonal anomalies. In the latter case, the soil moisture assimilation increased the $R_{\text {anom:subseas }}$ in the surface layer by a lesser amount than 


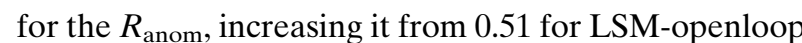
to 0.52 for LSM-DAland, while actually degrading the root-zone $R_{\text {anom:subseas, }}$ from 0.48 for LSM-openloop to 0.46 for LSM-DAland. While the very small differences between the metrics reported here makes any conclusions uncertain, these results suggest that the benefit gained by the root-zone soil moisture from the assimilation occurred at time scales longer than 31 days.

\section{b. The AGCM assimilation experiments}

\section{1) SOIL MOISTURE ASSIMILATION INCREMENTS AND MODEL RESPONSE}

The mean and standard deviation of the increments added to the model by the soil moisture assimilation in the AGCM-DAland/atmos experiment are shown in Fig. 5 for each month of the experiment. In general, the increments were relatively small, giving a global land average of the temporal mean increments of $-0.01 \mathrm{~mm}$ day $^{-1}$, and a global land average of the temporal standard deviations of the increments of $1.4 \mathrm{~mm}$ day $^{-1}$. Recall that the assimilated soil moisture observations were bias corrected over a much longer time period than the AGCM experiment period; hence the nonzero mean increment obtained here is not unexpected. Note also that the increments discussed here (and in Fig. 5) are those output from the EnKF. However, the actual amount of moisture added or subtracted in a given update cycle may differ from these values, as the actual increments are sometimes limited to avoid violating physical limitations in the model, such as the minimum and maximum model soil moisture. The largest (absolute) monthly mean increments (left column of Fig. 5) were around $2.0 \mathrm{~mm} \mathrm{day}^{-1}$. The monthly mean soil moisture increments were generally stronger in the Northern Hemisphere, with a tendency to remove moisture in the northern mid- and high latitudes in April and May, before adding moisture in July. As expected, the standard deviation of the increments generally exceeded the mean increment across each month, with maximum standard deviation values around $5.0 \mathrm{~mm}$ day $^{-1}$. For each month, the standard deviation of the daily increments (right column of Fig. 5) was generally largest in the more humid regions of the Northern Hemisphere (and to a lesser extent in the tropics), where the soil moisture itself typically has more variability.

For comparison, the adjustments made to the precipitation entering the land surface by the MERRA-2 precipitation correction scheme were larger than the soil moisture increments, although of the same order of magnitude. For example, for both AGCM assimilation experiments, the global land average of the mean precipitation correction at each grid cell was $1.0 \mathrm{~mm}$ day $^{-1}$, while the average of the temporal standard deviations was $5.1 \mathrm{~mm} \mathrm{day}^{-1}$. At the same time, the spatial distribution of the precipitation adjustments was very different from that of the soil moisture assimilation increments, with the largest precipitation adjustments occurring in the tropics [e.g., see Fig. 3b of Reichle et al. (2017b)].

Figure 6 shows the mean and standard deviation of the differences between the AGCM-DAland/atmos and AGCM-DAatmos experiments for the near-surface $(0-5 \mathrm{~cm})$ and root-zone $(0-100 \mathrm{~cm})$ soil moisture in June 2013 (after 2 months of assimilation). The differences in the root-zone soil moisture were largely limited to the Northern Hemisphere (Fig. 6c). In particular, the mean monthly root-zone soil moisture was reduced by up to $0.06 \mathrm{~m}^{3} \mathrm{~m}^{-3}$ in a region spanning from western Europe across southern Russia, and in the eastern United States. These same regions also experienced drying of the surface soil layer (Fig. 6a). Some arid regions also experienced relatively large wetting of the surface soil layer that is not seen in the root-zone soil moisture. In particular, over the Sahara the soil moisture assimilation increased the mean monthly surface soil moisture by around $0.05 \mathrm{~m}^{3} \mathrm{~m}^{-3}$. In Fig. 5 the net (absolute) increments to the soil profile in this region were generally below $<0.4 \mathrm{~mm} \mathrm{day}^{-1}$. Unlike traditional layer-based land surface models, the Catchment model simulates soil moisture as an equilibrium profile and as deviations from that profile (Koster et al. 2000), and examining the increments added to each of these variables shows that the increased surface soil moisture over the Sahara was due to the addition of positive mean monthly increments (of around $0.3-0.5 \mathrm{~mm} \mathrm{day}^{-1}$ ) to the surface excess variable in each month of the experiment.

Figure 7 shows similar maps for the model response to the soil moisture assimilation in June, for a range of near-surface fields, namely the latent heat flux, $T_{\max }^{2 \mathrm{~m}}$, $q^{2 \mathrm{~m}}$, and precipitation. For each of the variables plotted, the standard deviation of the differences was generally larger than the mean of the differences, indicating a greater impact on the day-to-day variability than on the monthly means (despite the soil moisture mean difference within each month exceeding the standard deviations in Fig. 6). With the exception of precipitation, the mean monthly differences in Fig. 7 show a strong visual correspondence to the mean monthly differences in soil moisture in Fig. 6, suggesting a strong local response in the boundary layer to the soil moisture changes induced by the soil moisture assimilation. In general, the regions where the AGCM-DAland/atmos experiment was drier than AGCM-DAatmos in Fig. 6 also showed the expected decrease in latent heat, and consequent increase in $T_{\max }^{2 \mathrm{~m}}$ and decrease in $q^{2 \mathrm{~m}}$ (with the opposite pattern occurring where AGCM-DAland/atmos was 


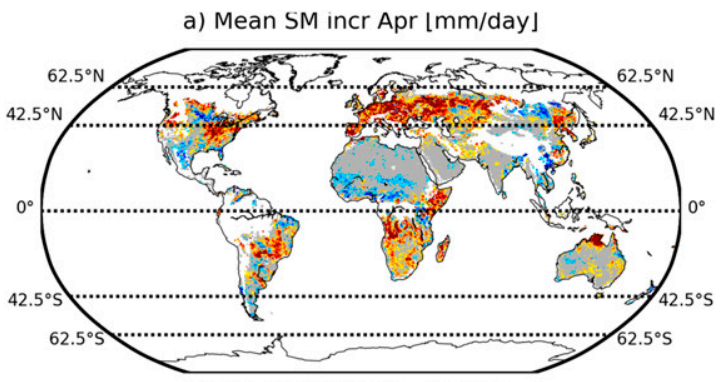

c) Mean SM incr May [mm/day]

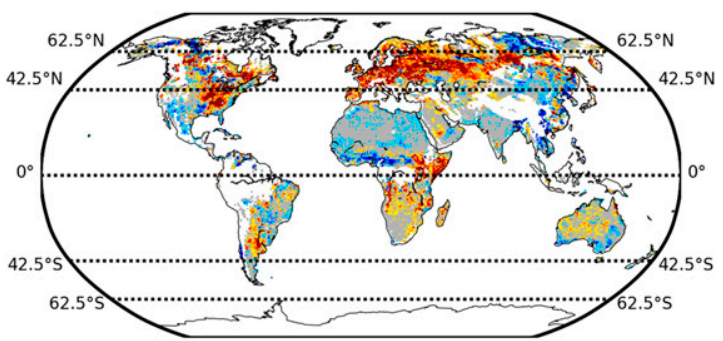

e) Mean SM incr Jun [mm/day ]

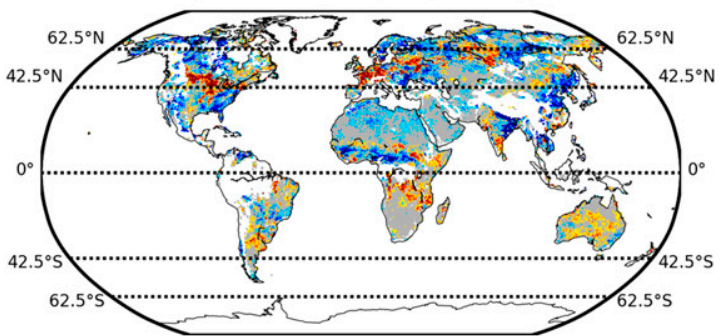

g) Mean SM incr Jul [mm/day]

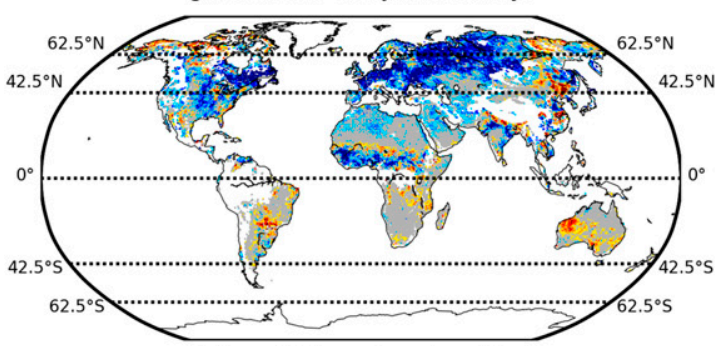

i) Mean SM incr Aug [mm/day」
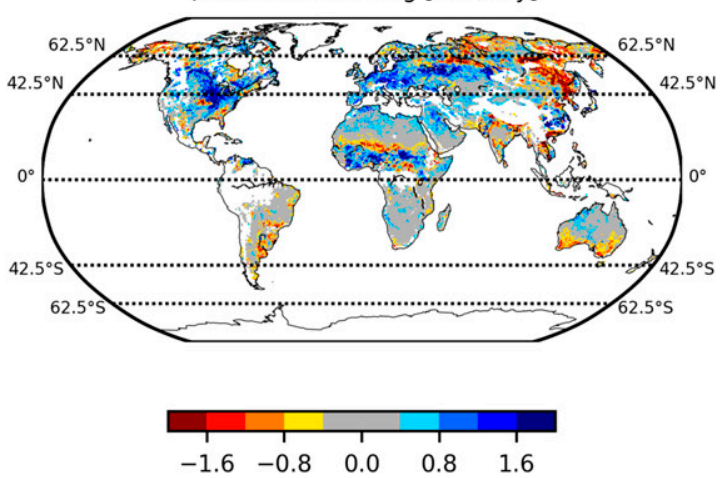

b) Stdev SM incr Apr [mm/day]

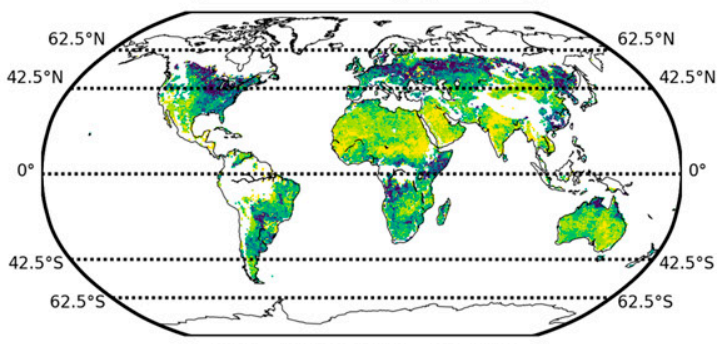

d) Stdev SM incr May [mm/day]

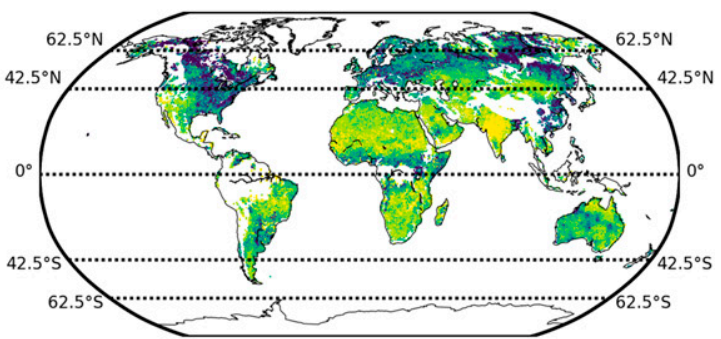

t) Stdev SM incr Jun [mm/day]

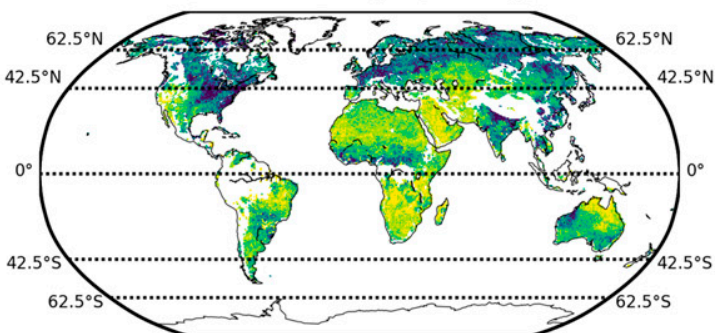

h) Stdev SM incr Jul [mm/day]

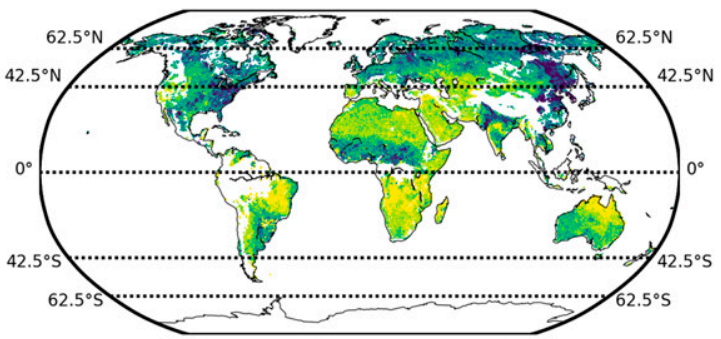

j) Stdev SM incr Aug [mm/day]
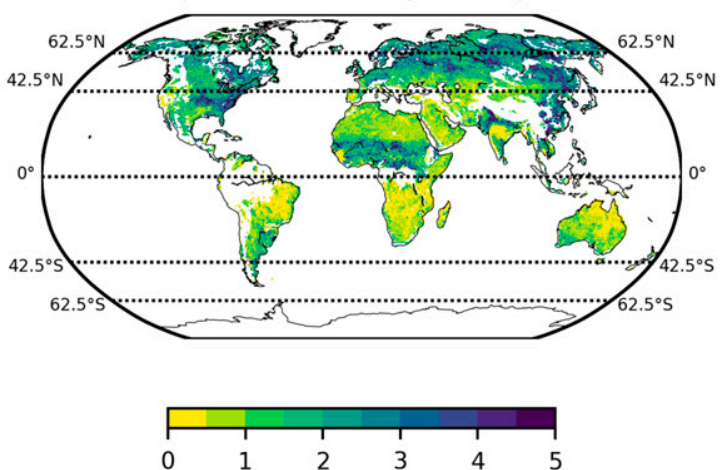

FIG. 5. (left) Mean and (right) standard deviation over each month of the net soil moisture increments calculated by the soil moisture assimilation in the AGCM-DAland/atmos experiment. 

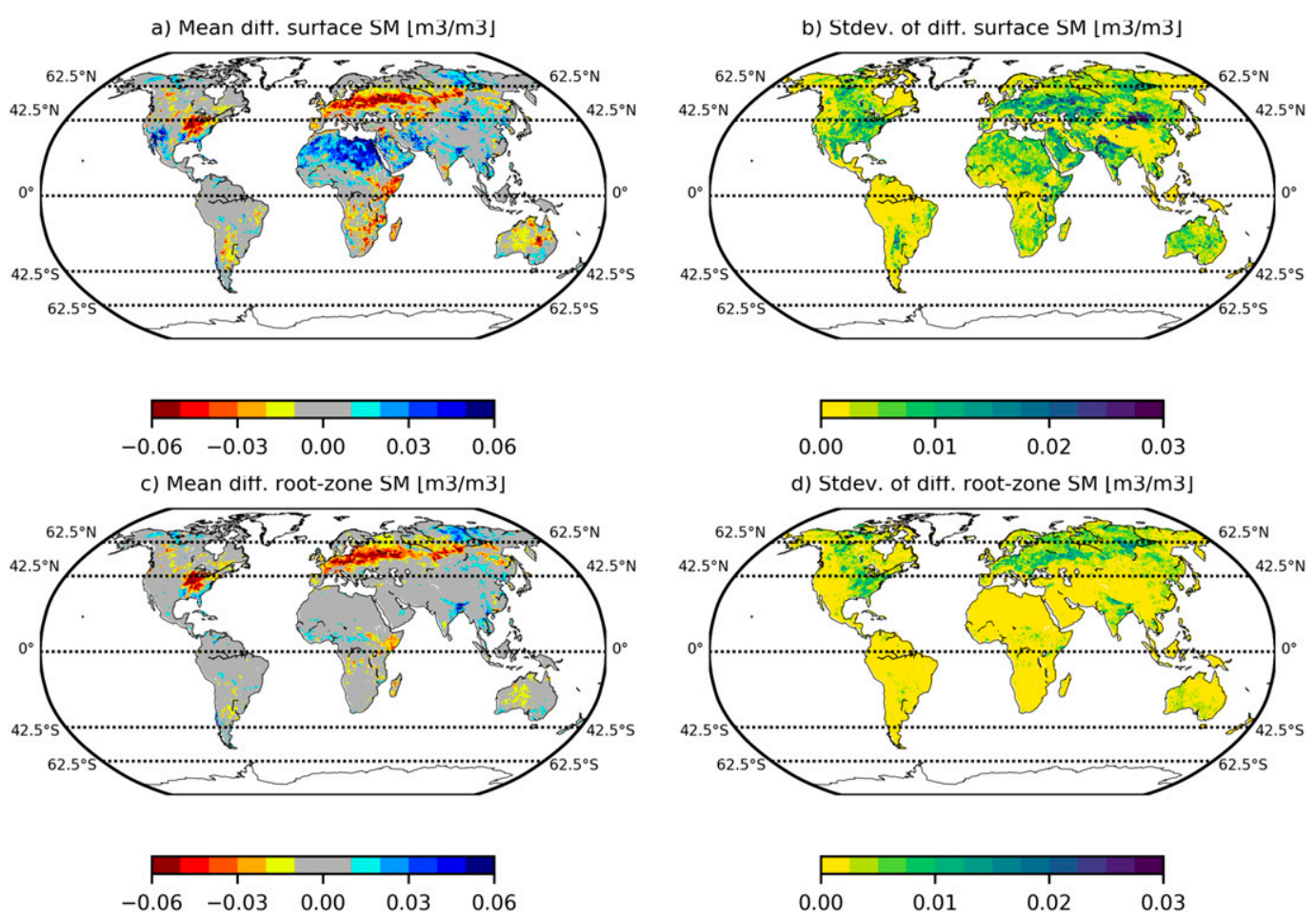

FIG. 6. (left) Mean and (right) standard deviation of the daily difference (AGCM-DAland/atmos minus AGCM-DAatmos) over June 2013 between the (top) surface soil moisture and (bottom) root-zone soil moisture.

wetter). Most notably, across southern Russia, where the soil moisture has been decreased by up to $0.06 \mathrm{~m}^{3} \mathrm{~m}^{-3}$, the latent heating was decreased by around $20 \mathrm{~W} \mathrm{~m}^{-2}$, resulting in a $T_{\max }^{2 \mathrm{~m}}$ increase of more than $0.5 \mathrm{~K}$ and a $q^{2 \mathrm{~m}}$ reduction of more than $1 \mathrm{~g} \mathrm{~kg}^{-1}$. There was a slight decrease in precipitation across the same region, although in general the response of precipitation to the assimilation does not show a visual relationship to the local soil moisture changes, and the precipitation mean difference maps are dominated by the tropics, where precipitation itself is much larger.

Finally, the relatively large response to the soil moisture assimilation over the Sahara is concerning. In such an arid environment, soil moisture is expected to persist close to its lower limit, with evapotranspiration remaining close to zero. Assimilating soil moisture observations would not be expected to substantially change this situation. And yet, in Fig. 7 the wetting of the surface soil layer over the Sahara (by about $0.05 \mathrm{~m}^{3} \mathrm{~m}^{-3}$, or $2.5 \mathrm{~mm}$ over the $5-\mathrm{cm}$ surface layer) corresponds to locally increased latent heating (by $5-15 \mathrm{~W} \mathrm{~m}^{-2}$, equivalent to $0.2-0.5 \mathrm{~mm} \mathrm{day}^{-1}$ ), reduced $T_{\max }^{2 \mathrm{~m}}$ (by around $0.5 \mathrm{~K}$ ), and increased $q^{2 \mathrm{~m}}$ (by around $0.5 \mathrm{~g} \mathrm{~kg}^{-1}$ ), particularly in the eastern Sahara. This issue will be further investigated in section $3 b(4)$.

\section{2) EvaluAtion OF SURFACE FLUXES}

Assimilating soil moisture observations in AGCMDAland/atmos improved both the latent and sensible heat fluxes, although by only a small amount compared to the AGCM-DAatmos RMSE, as shown in Fig. 8. For latent heating, the mean RMSE across the 29 FLUXNET2015 sites was significantly decreased from $34.2 \mathrm{~W} \mathrm{~m}^{-2}$ for AGCM-DAatmos to $32.6 \mathrm{~W} \mathrm{~m}^{-2}$ for AGCM-DAland/atmos (for details of significance testing, see section 2c). Likewise, for sensible heating the mean RMSE was significantly reduced from $37.7 \mathrm{~W} \mathrm{~m}^{-2}$ to $36.5 \mathrm{~W} \mathrm{~m}^{-2}$. The middle and right columns of the scatterplots in Fig. 8 show the contribution of the bias and ubRMSE to the RMSE, demonstrating that the improved RMSE in AGCM-DAland/atmos was due to reduced biases over the experiment period rather than reduced ubRMSE. That is, the improvement is largely in the mean over the experiment period, rather than in the day-to-day variability. For AGCM-DAatmos, the latent heat was generally biased high and the sensible heat was generally biased low during the AGCM-DAatmos experiment, and the soil moisture assimilation reduced these biases at most locations. Averaged over all sites, the net effect was to significantly reduce the mean absolute bias over the experiment period, from 
a) Mean ditt. latent heat [W/m2]
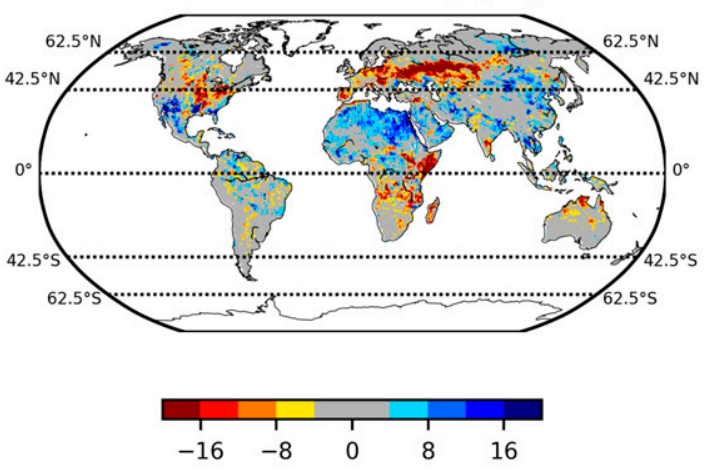

c) Mean ditt. daily max T2m [K]
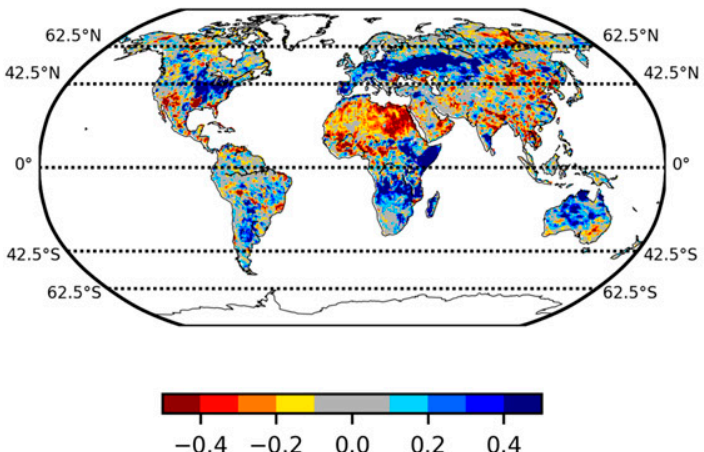

e) Mean ditt. specitic humid. [g/kg]
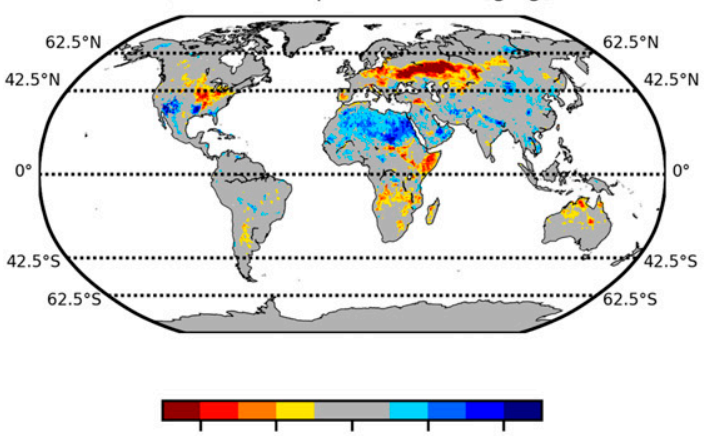

$\begin{array}{lllll}-0.8 & -0.4 & 0.0 & 0.4 & 0.8\end{array}$

g) Mean dift. AGCM precip. [mm/day」
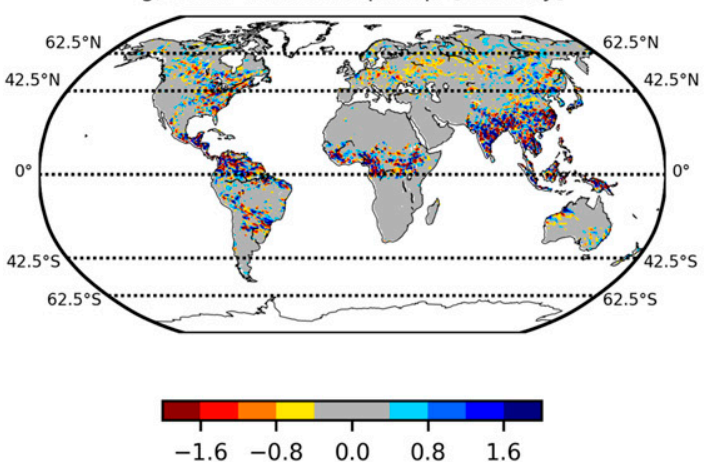

b) Stdev. of ditt. latent heat [W/m2]
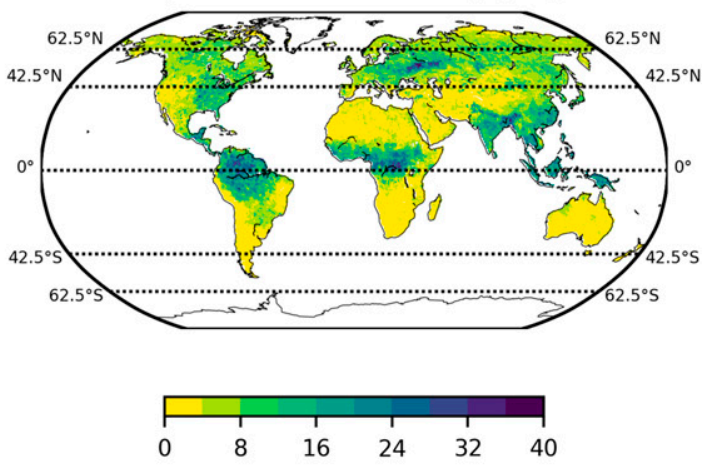

d) Stdev. of ditt. daily $\max T 2 \mathrm{~m}[\mathrm{~K}]$
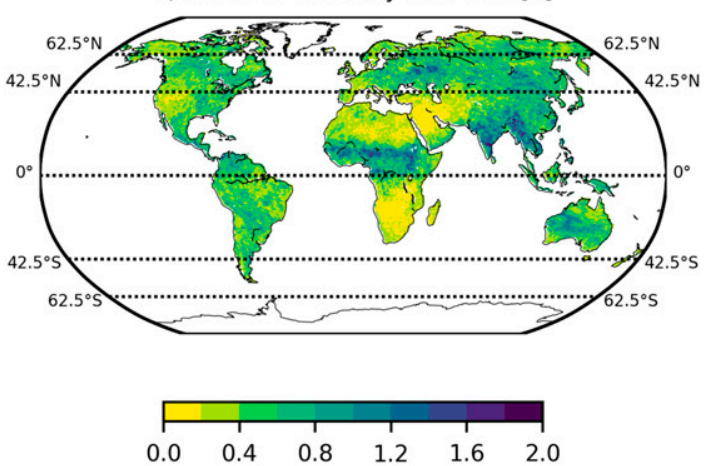

†) Stdev. of ditt. specitic humid. $[\mathrm{g} / \mathrm{kg}$ ]
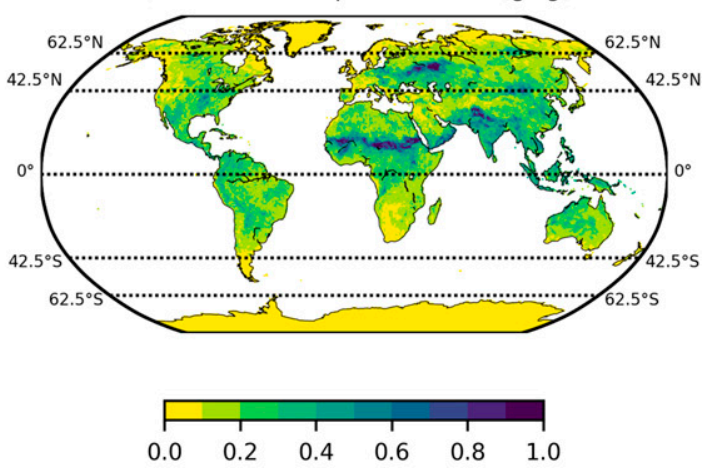

h) Stdev. ot ditt. AGCM precip. [mm/day]
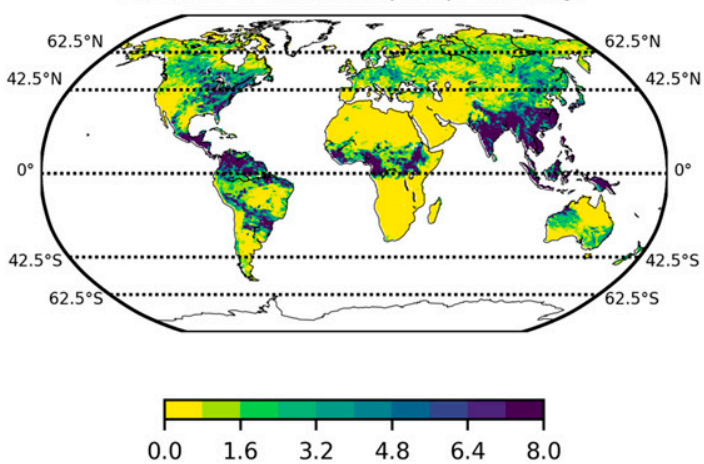

FIG. 7. (left) Mean and (right) standard deviation of the daily difference (AGCM-DAland/atmos minus AGCM-DAatmos) over June 2013 between the (from top to bottom) latent heat, daily $T_{\max }^{2 \mathrm{~m}}, q^{2 \mathrm{~m}}$, and precipitation. 
a) RMSE LH $[\mathrm{W} / \mathrm{m} 2]$

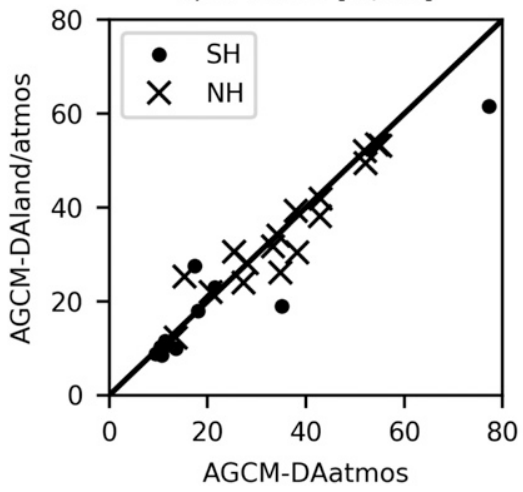

d) RMSE SH $[\mathrm{W} / \mathrm{m} 2]$

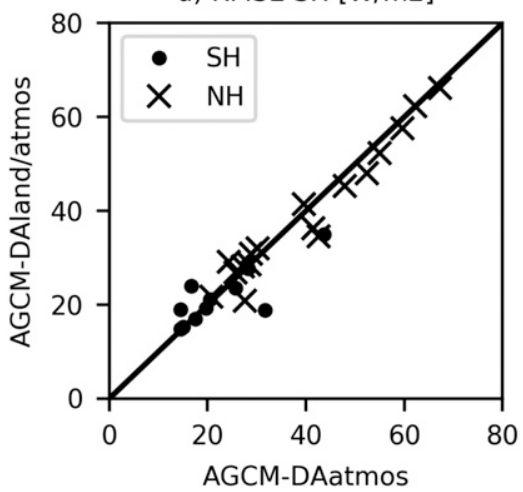

b) bias LH $[\mathrm{W} / \mathrm{m} 2]$

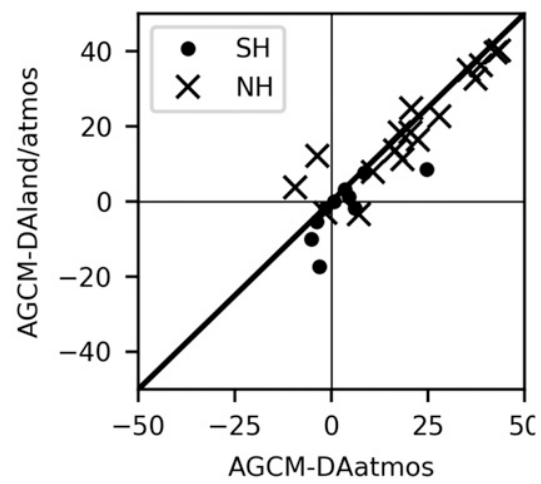

e) bias $\mathrm{SH}[\mathrm{W} / \mathrm{m} 2]$

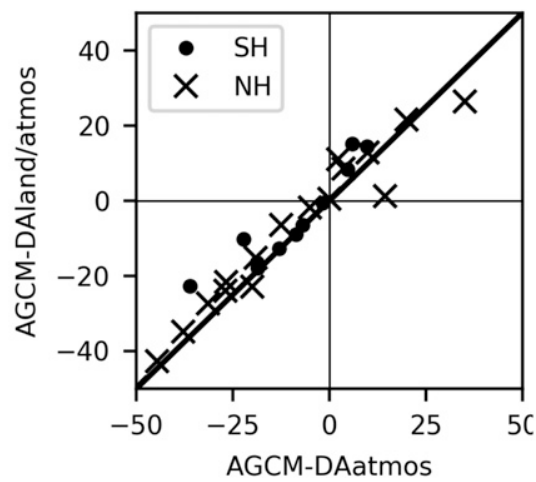

c) ubRMSE LH $[\mathrm{W} / \mathrm{m} 2]$

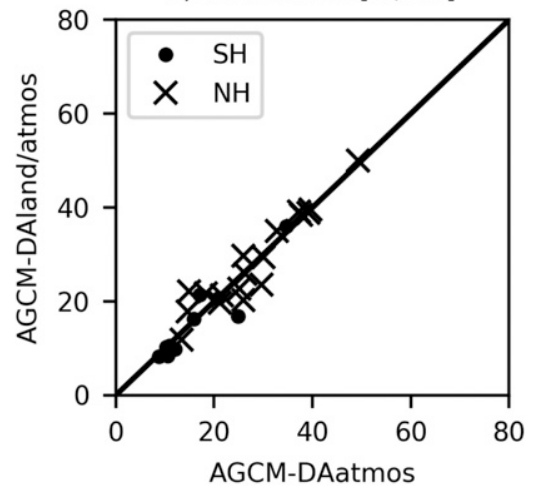

f) ubRMSE SH $[\mathrm{W} / \mathrm{m} 2]$

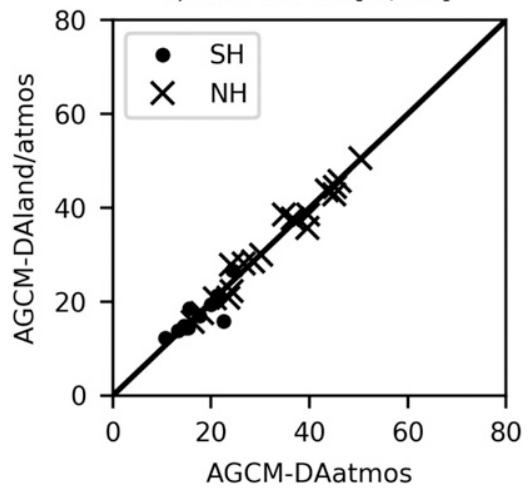

FIG. 8. Scatterplot of (left) RMSE, (middle) bias, and (right) ubRMSE between daily FLUXNET2015 observations and output from the AGCM-DAatmos and AGCM-DAland/atmos experiments, for (top) latent heat and (bottom) sensible heat. Statistics are calculated from 14 Apr to 31 Aug 2013, and data for the Southern Hemisphere (SH) and Northern Hemisphere (NH) are shown separately.

$22.2 \mathrm{~W} \mathrm{~m}^{-2}$ (AGCM-DAatmos) to $20.0 \mathrm{~W} \mathrm{~m}^{-2}$ (AGCMDAland/atmos) for latent heating, and from 22.9 to $21.3 \mathrm{~W} \mathrm{~m}^{-2}$ for sensible heating. By contrast, the assimilation had a much smaller impact on the ubRMSE, with the mean ubRMSE being reduced from 23.4 to $23.3 \mathrm{~W} \mathrm{~m}^{-2}$ for latent heating, and from 27.0 to $26.8 \mathrm{~W} \mathrm{~m}^{-2}$ for sensible heating (with neither change being significant).

\section{3) Evaluation of 2-M TEMPERATURE AND SPECIFIC HUMIDITY}

Figures 9a and 10a show the RMSE for the AGCMDAatmos experiment, calculated against the GHCN and HadISD datasets, for $T_{\max }^{2 \mathrm{~m}}$ and $q^{2 \mathrm{~m}}$, respectively. There is little regional correspondence between the RMSE in the temperature and that in the humidity. On the other hand, the biases over the AGCM-DAatmos experiment (Figs. 9c and 10c) show a tendency toward being too cool and wet in the high latitudes, with the opposite pattern in the midlatitudes. For both $T_{\max }^{2 \mathrm{~m}}$ and $q^{2 \mathrm{~m}}$, the soil moisture assimilation had a modest impact on the RMSE (Figs. 9b and 10b). For $T_{\max }^{2 \mathrm{~m}}$, the soil moisture assimilation significantly changed the RMSE at $35 \%$ of the evaluated model grid cells, and $65 \%$ of the significant changes were toward improved RMSE in AGCM-DAland/atmos. For $q^{2 \mathrm{~m}}, 46 \%$ of the grid cells were significantly changed, with $78 \%$ of those significant changes being improvements. Globally averaged over all available stations, the mean RMSE was very slightly reduced by the soil moisture assimilation for both variables, from 2.82 to $2.79 \mathrm{~K}$ for $T_{\max }^{2 \mathrm{~m}}$ and from 1.25 to $1.20 \mathrm{~g} \mathrm{~kg}^{-1}$ for $q^{2 \mathrm{~m}}$. Locally, the changes were much larger, and also showed similar regional patterns of change in both $T_{\max }^{2 \mathrm{~m}}$ and $q^{2 \mathrm{~m}}$. Of most note, the soil moisture assimilation in the AGCM-DAland/atmos experiment reduced the RMSE across a large area spanning from western Europe across southern Russia and in a smaller region in the south-central United States, by $0.1-0.4 \mathrm{~K}$ for $T_{\max }^{2 \mathrm{~m}}$ (up to $20 \%$ of the AGCM-DAatmos value) and $0.1-0.5 \mathrm{~g} \mathrm{~kg}^{-1}$ for $q^{2 \mathrm{~m}}$ (up to $40 \%$ of the AGCMDAatmos value).

As with the surface flux evaluation, the improved RMSE in the AGCM-DAland/atmos experiment was largely due to reduced biases over the experiment period, 
a) AGCM-DAatmos T2m-max RMSE [K]
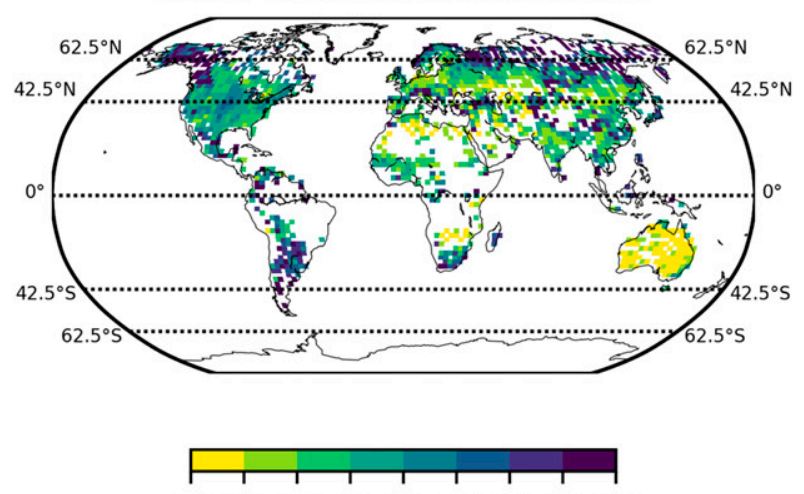

$\begin{array}{lllllllll}1.0 & 1.5 & 2.0 & 2.5 & 3.0 & 3.5 & 4.0 & 4.5 & 5.0\end{array}$

c) AGCM-DAatmos T2m-max bias [K]
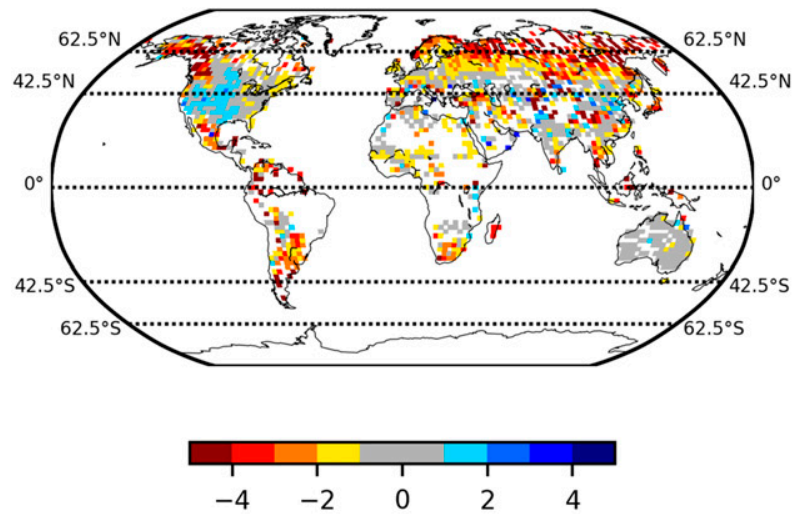

e) ACGM-DAatmos T2m-max ubRMSE [K]
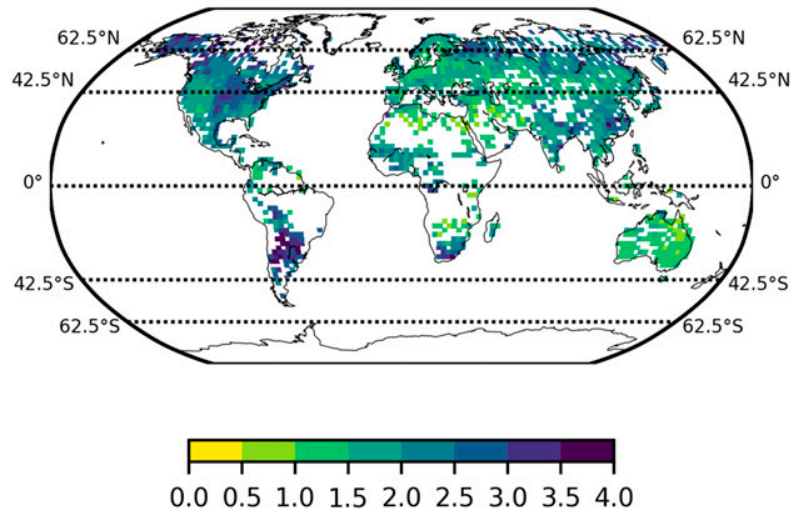

b) Difference in T2m-max RMSE [K]
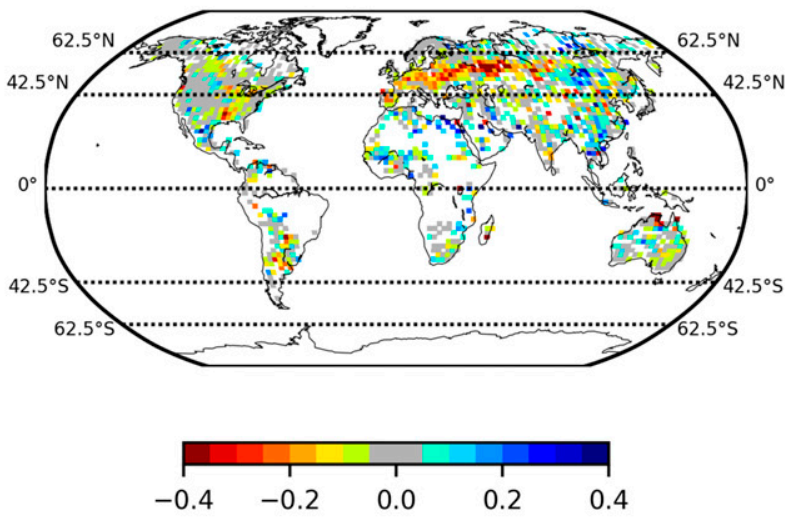

d) Difference in T2m-max |bias $[\mathrm{K}]$
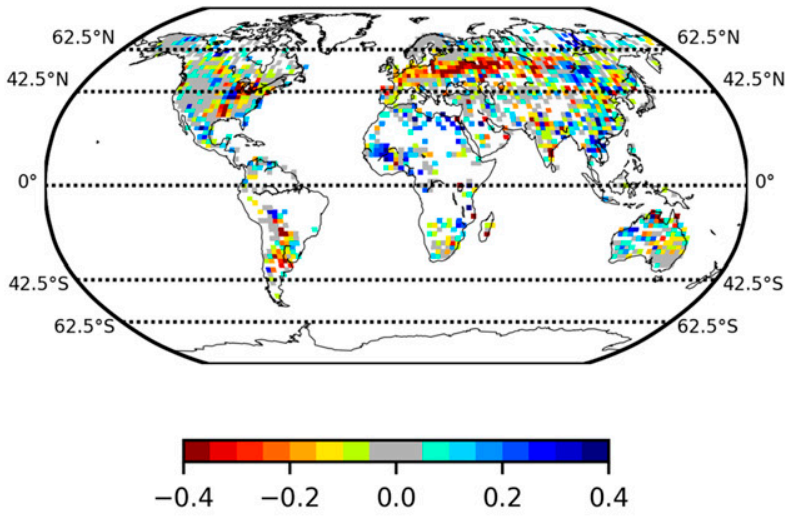

f) Difference in T2m-max ubRMSE [K]
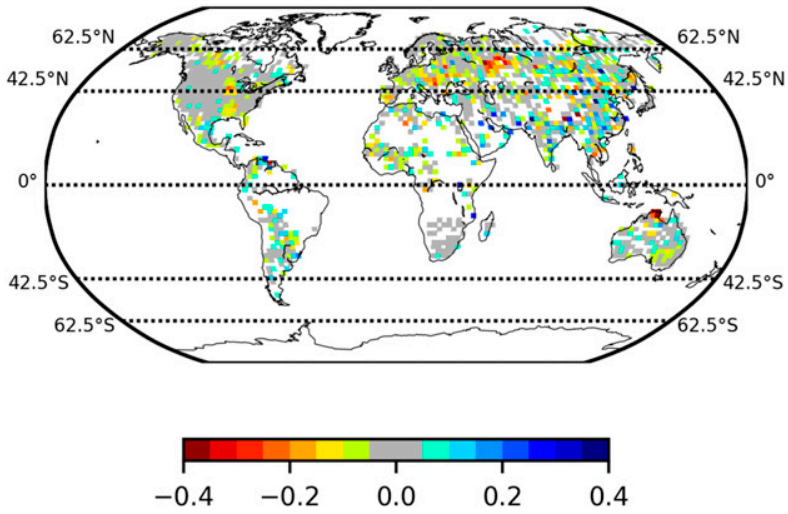

FIG. 9. $T_{\max }^{2 \mathrm{~m}}$ evaluation statistics vs GHCN observations for (left) AGCM-DAatmos, and (right) the difference in the statistics where difference equals (AGCM-DAland/atmos statistic - AGCM-DAatmos statistic), for (top) RMSE, (middle) bias, and (bottom) ubRMSE. All statistics are calculated from 14 Apr to 31 Aug 2013, and for clarity, the $0.5^{\circ}$ by $0.625^{\circ}$ results have been coarsened up to a $2.0^{\circ} \times 2.5^{\circ}$ grid before mapping.

for both $T_{\max }^{2 \mathrm{~m}}$ (cf. Figs. 9b,d) and $q^{2 \mathrm{~m}}$ (cf. Figs. 10b,d). In particular, the large region of reduced RMSEs across southern Russia was due to reduced biases (in this case, cool and wet biases). Note that there were also several small patches of increased biases, for example over Mongolia, Thailand, and southwest Mali. Globally averaged, the mean absolute biases over the experiment period are very slightly reduced by the soil 
a) AGCM-DAatmos q2m RMSE $[\mathrm{g} / \mathrm{kg}]$
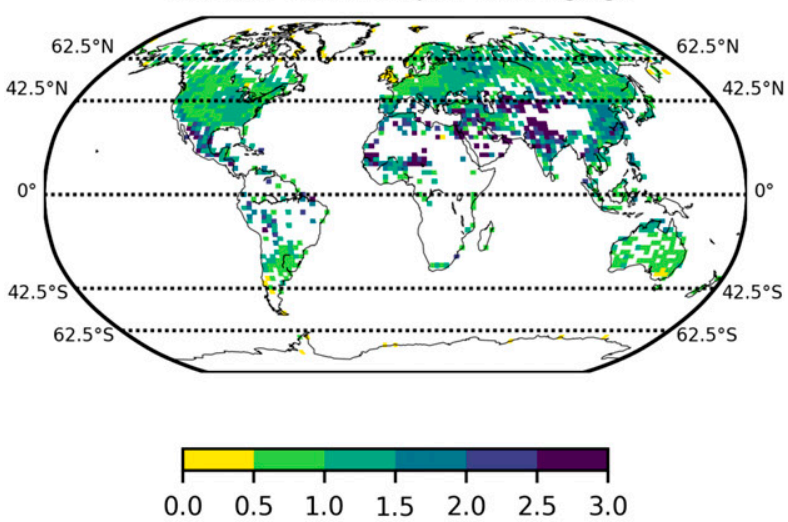

c) AGCM-DAatmos $\mathrm{q} 2 \mathrm{~m}$ bias $[\mathrm{g} / \mathrm{kg}]$
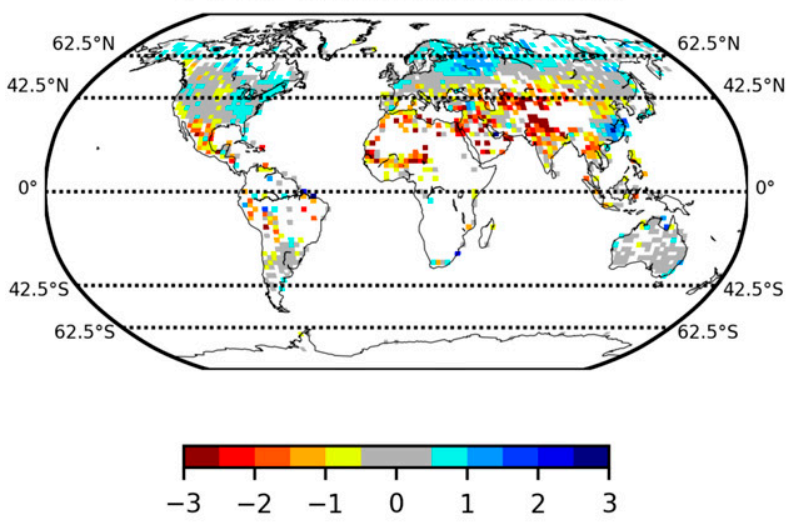

e) ACGM-DAatmos q2m ubRMSE $[\mathrm{g} / \mathrm{kg}]$
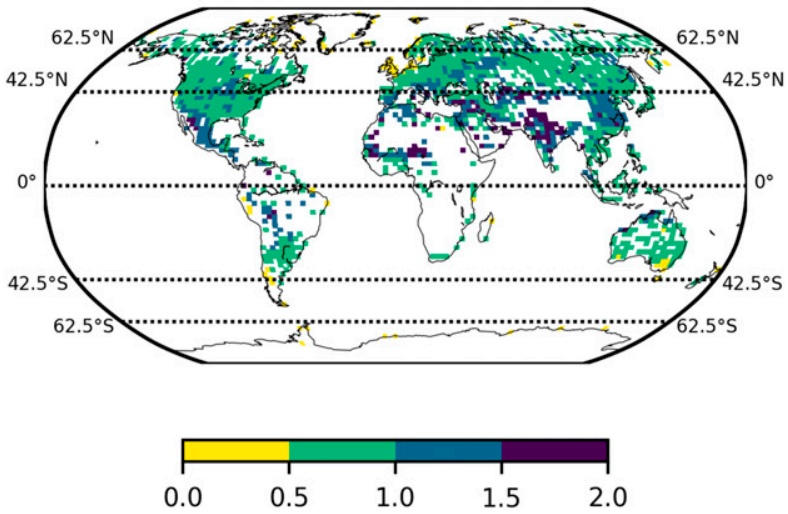

b) Difference in q2m RMSE $[\mathrm{g} / \mathrm{kg}]$
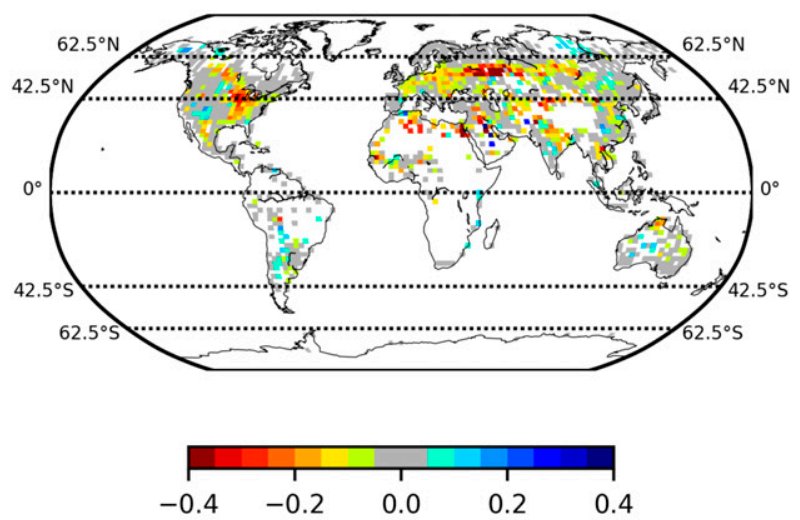

d) Difference in q2m |bias $\mid \mathrm{g} / \mathrm{kg}]$
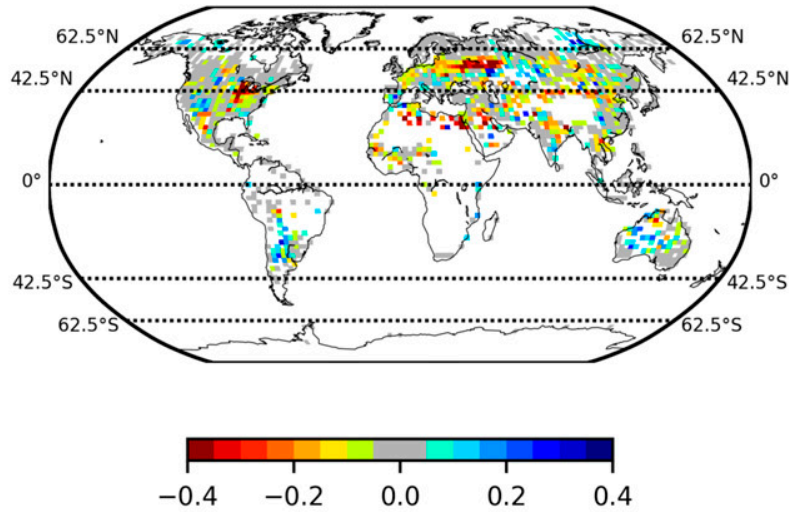

f) Difference in q2m ubRMSE $[\mathrm{g} / \mathrm{kg}]$
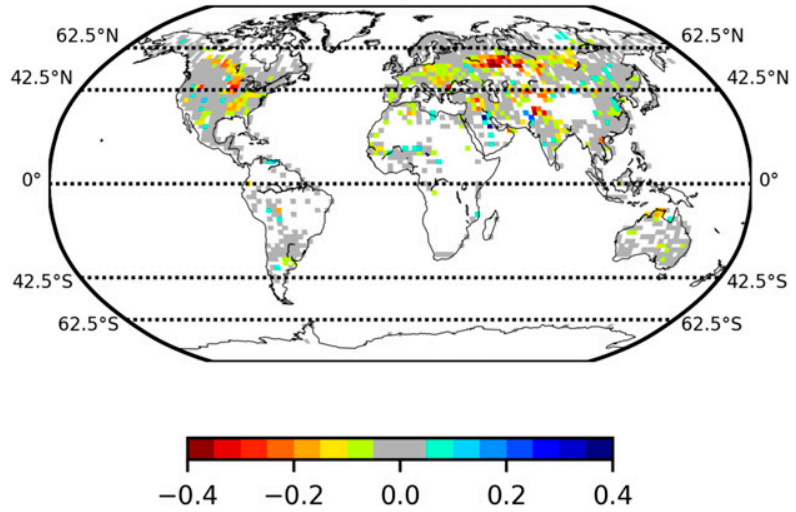

FIG. 10. As in Fig. 9, but for $q^{2 \mathrm{~m}}$ evaluated against HadISD observations.

moisture assimilation, from 1.62 to $1.59 \mathrm{~K}$ for $T_{\max }^{2 \mathrm{~m}}$ and from 0.75 to $0.71 \mathrm{~g} \mathrm{~kg}^{-1}$ for $q^{2 \mathrm{~m}}$. The ubRMSE the changes induced by the soil moisture assimilation were also small (Figs. 9f and 10f), and the mean ubRMSE was also very slightly reduced, from 2.05 to $2.04 \mathrm{~K}$ for $T_{\max }^{2 \mathrm{~m}}$, and from 0.91 to $0.88 \mathrm{~g} \mathrm{~kg}^{-1}$ for $q^{2 \mathrm{~m}}$.
Maps were also plotted for the RMSE, bias, and ubRMSE within each individual calendar month of the experiment period (not shown). These maps revealed the same result as in Figs. 9 and 10-the RMSE was reduced for each month largely because of reduced monthly biases. 


\section{4) TIME SERIES EXAMPLES}

Here, example time series are presented at three locations to demonstrate the different ways in which the soil moisture assimilation can affect the AGCM output, and how the assimilation innovations relate back to the information in the assimilated observations. The first example, shown in Fig. 11, is in southwest Ukraine, which is representative of the large region of improved $T_{\max }^{2 \mathrm{~m}}$ and $q^{2 \mathrm{~m}}$ spanning western Europe through southern Russia in Figs. 9b and 10b. At this location, the $T_{\max }^{2 \mathrm{~m}}$ RMSE was reduced from $2.32 \mathrm{~K}$ for AGCM-DAatmos to $1.78 \mathrm{~K}$ for AGCM-DAland/atmos, while the $q^{2 \mathrm{~m}}$ RMSE was decreased from 1.24 to $0.91 \mathrm{~g} \mathrm{~kg}^{-1}$. In both cases, the reduced RMSE is due largely to a reduced bias over the experiment period. For the $T_{\max }^{2 \mathrm{~m}}$, this is shown in Fig. 11d (the $q^{2 \mathrm{~m}}$ time series are not shown for brevity). Returning to the assimilation, by reducing the surface and root-zone soil moisture (Figs. 11a,b) the soil moisture assimilation shifted the surface flux partition away from latent heating (Fig. 11c) and toward increased sensible heating, reducing the cool bias over the experiment (Fig. 11d). Additionally, Fig. 12 shows the LSM-openloop and assimilated (bias corrected) soil moisture observations (in this case, only from ASCAT) at the same location over the full LSM experiment period, together with the MERRA-2 and GHCN $T_{\max }^{2 \mathrm{~m}}$. The model was unusually wet in 2013 at the start of the AGCM assimilation experiment, resulting in a large positive soil moisture bias that persisted through the first half of the experiment period. Coinciding with this wet bias, the MERRA-2 $T_{\max }^{2 \mathrm{~m}}$ was also unusually cool resulting in a larger than usual springtime $T_{\max }^{2 \mathrm{~m}}$ cool bias. Taken together, Figs. 11 and 12 strongly suggest that the model soil moisture was overestimated in the summer of 2013, resulting in an increased daytime cool bias, and that the elevated soil moisture was correctly reduced by the soil moisture assimilation, thus reducing the $T_{\max }^{2 \mathrm{~m}}$ bias in the AGCM-DAland/atmos experiment.

Figures 13 and 14 show similar time series for a location in the south-central United States, where the $T_{\max }^{2 \mathrm{~m}}$ RMSE was reduced from $4.00 \mathrm{~K}$ for AGCM-DAatmos to $3.38 \mathrm{~K}$ for AGCM-DAland/atmos. In this case, the soil moisture assimilation decreased the warm $T_{\max }^{2 \mathrm{~m}}$ bias over the AGCM assimilation experiment period (Fig. 13d) by wetting the soil (Figs. 13a,b), leading to decreased sensible heating and increased latent heating (Fig. 13c). Over the longer period, comparing the soil moisture bias (Fig. 14b) and the $T_{\max }^{2 \mathrm{~m}}$ model bias (Fig. 14d) shows a clear pattern of opposing biases between the two. In particular, during the summer months the model was consistently drier than the assimilated soil moisture

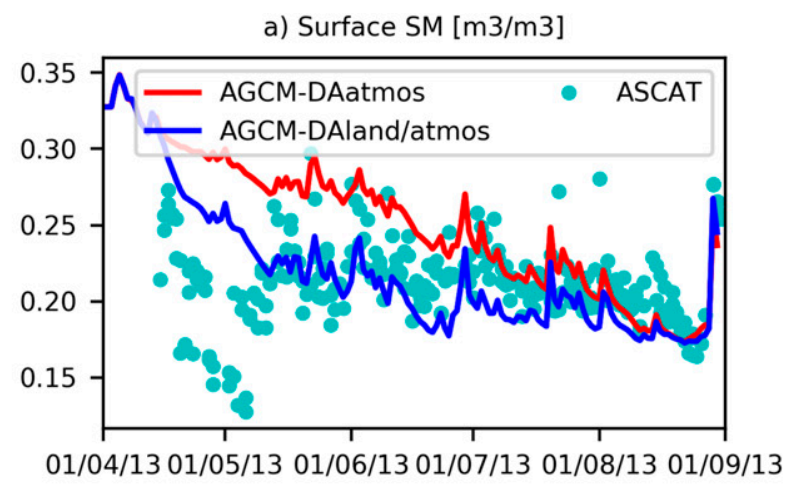

b) Root-zone SM $[\mathrm{m} 3 / \mathrm{m} 3]$

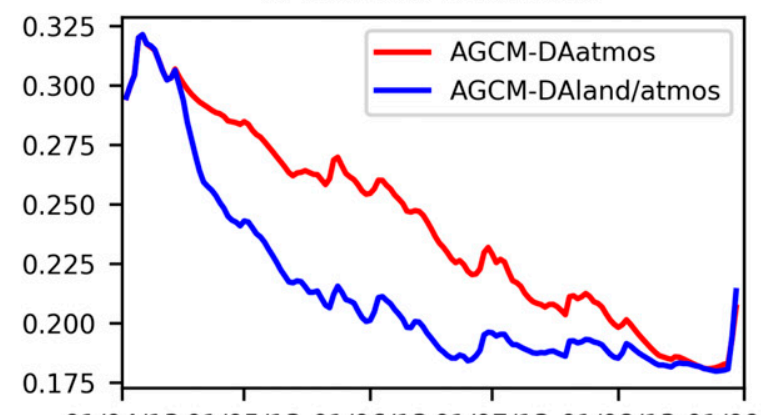

01/04/13 01/05/13 01/06/13 01/07/13 01/08/13 01/09/13

c) Latent heat $[\mathrm{W} / \mathrm{m} 2]$

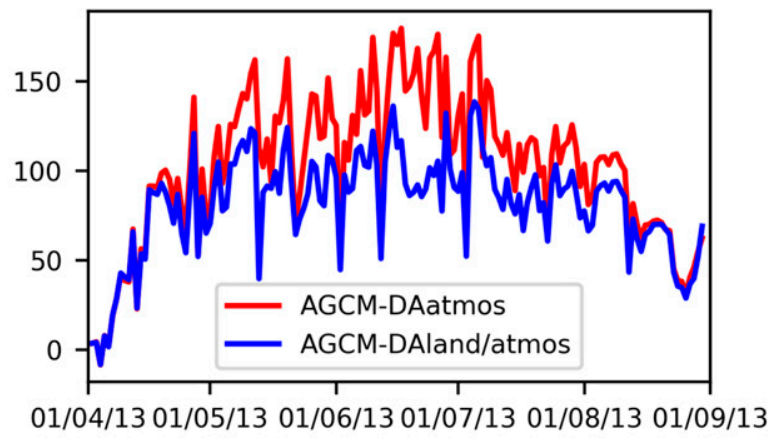

d) Daily max T2m bias [K]

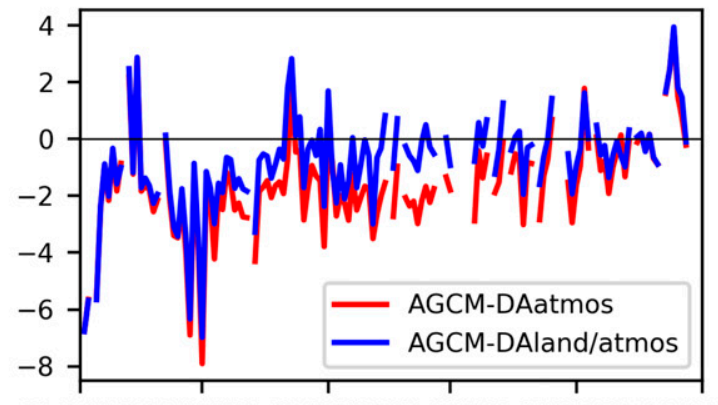

01/04/13 01/05/13 01/06/13 01/07/13 01/08/13 01/09/13

FIG. 11. Time series of the (a) surface soil moisture for the AGCM assimilation experiments and the assimilated soil moisture observations, (b) root-zone soil moisture from the AGCM assimilation experiments, (c) latent heat from the AGCM assimilation experiments, and (d) $T_{\max }^{2 \mathrm{~m}}$ bias compared to GHCN observations for the AGCM assimilation experiments at $\left(50.5^{\circ} \mathrm{N}, 30.6^{\circ} \mathrm{E}\right)$ in the Ukraine. 

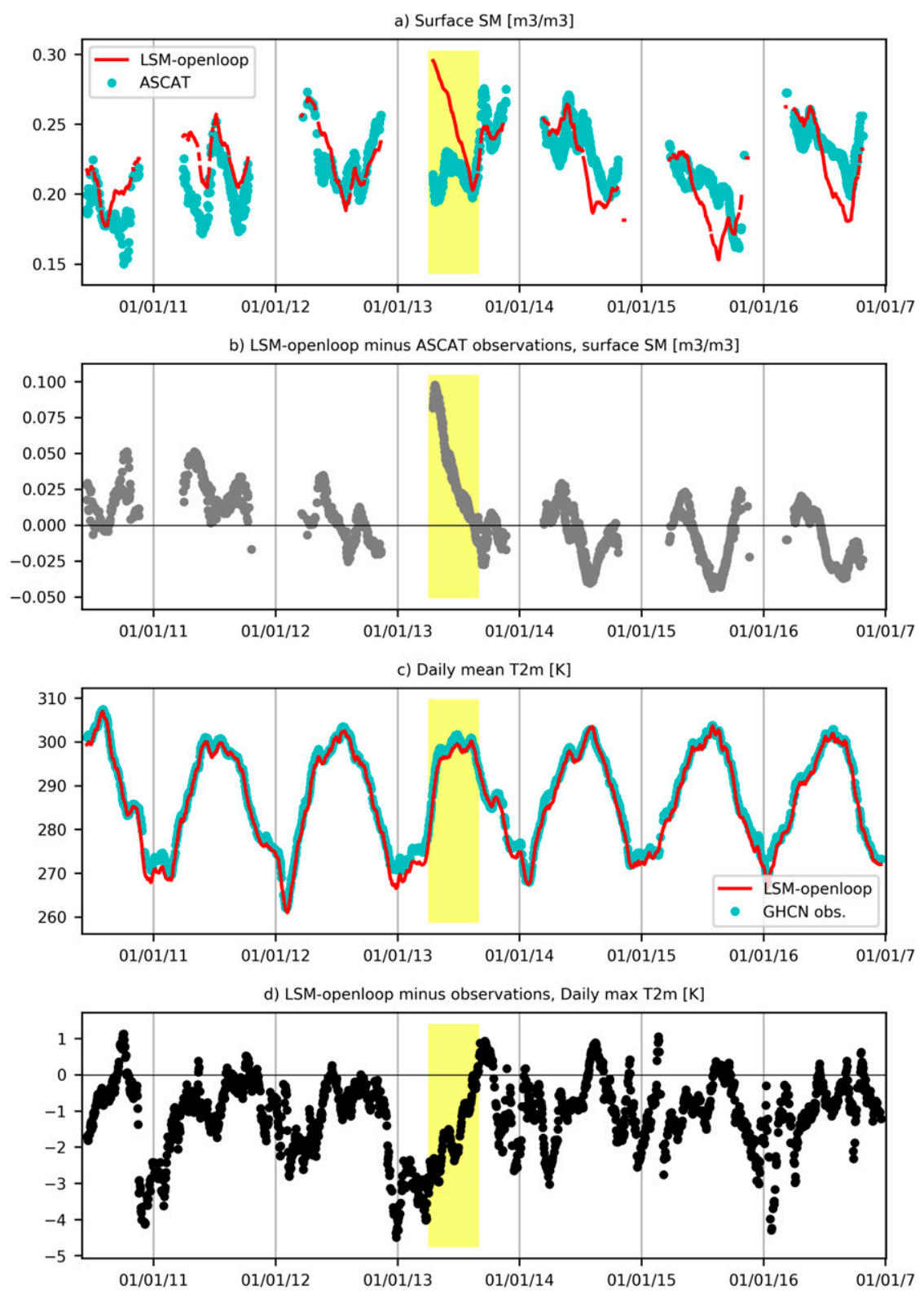

FIG. 12. Time series of (a) surface soil moisture from LSM-openloop and the assimilated soil moisture observations, (b) the difference between LSM-openloop and the assimilated soil moisture, (c) the $T_{\max }^{2 \mathrm{~m}}$ from MERRA-2 and the GHCN observations, and (d) the difference between the MERRA-2 and GHCN $T_{\max }^{2 \mathrm{~m}}$, at $\left(50.5^{\circ} \mathrm{N}, 30.6^{\circ} \mathrm{E}\right)$ in the Ukraine. The yellow shading indicates the period of the AGCM assimilation experiments. For clarity, all data are plotted as 30-day moving averages.

observations (again only from ASCAT), and also warmer than the GHCN $T_{\max }^{2 \mathrm{~m}}$ observations. Hence, the AGCM assimilation experiment wetted the soil, reducing this warm bias. However, another feature that stands out in Fig. 14 is that the years with the greatest summertime $T_{\max }^{2 \mathrm{~m}}$ biases do not correspond to the years with the greatest soil moisture biases, highlighting that not all $T_{\max }^{2 \mathrm{~m}}$ errors are associated with local soil moisture errors.
The final example, plotted in Figs. 15 and 16, is in Algeria, on the edge of the Sahara. At this location the $T_{\max }^{2 \mathrm{~m}}$ RMSE was increased from $2.05 \mathrm{~K}$ for AGCMDAatmos to $2.31 \mathrm{~K}$ for AGCM-DAland/atmos, and as previously noted in section $3 \mathrm{~b}(1)$ the AGCM-DAland/ atmos experiment induced unexpectedly large changes in the latent heating, $T_{\max }^{2 \mathrm{~m}}$, and $q^{2 \mathrm{~m}}$ across much of the Sahara. These changes are evident in the time series in Fig. 15, in 
a) Surface SM $[\mathrm{m} 3 / \mathrm{m} 3]$

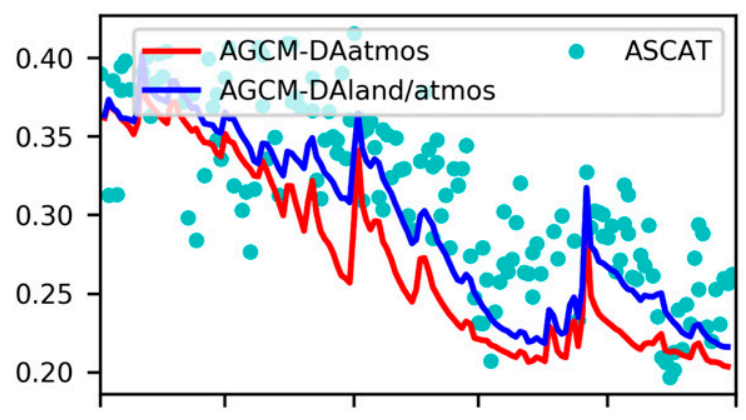

01/04/13 01/05/13 01/06/13 01/07/13 01/08/13 01/09/13

b) Root-zone SM [m3/m3]

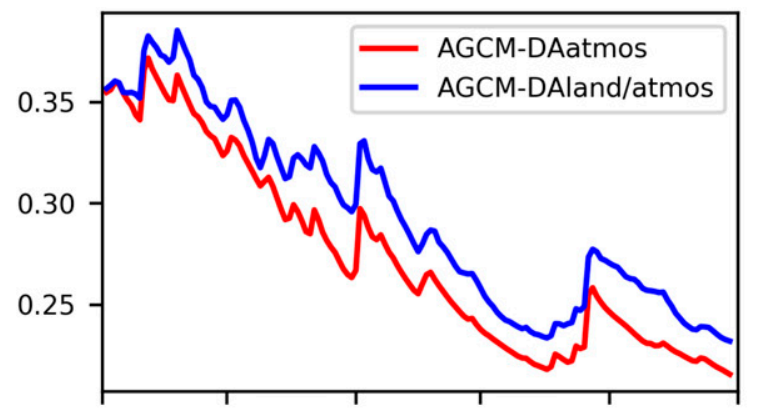

01/04/13 01/05/13 01/06/13 01/07/13 01/08/13 01/09/13

c) Latent heat $[\mathrm{W} / \mathrm{m} 2]$

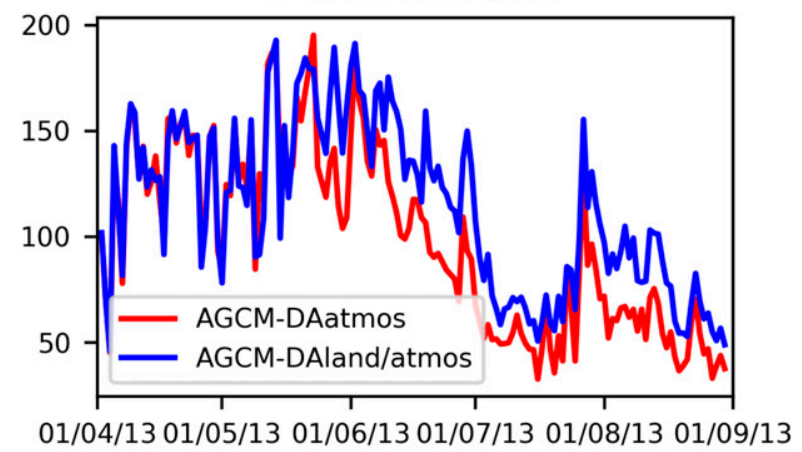

d) Daily max $\mathrm{T} 2 \mathrm{~m}$ bias [K]

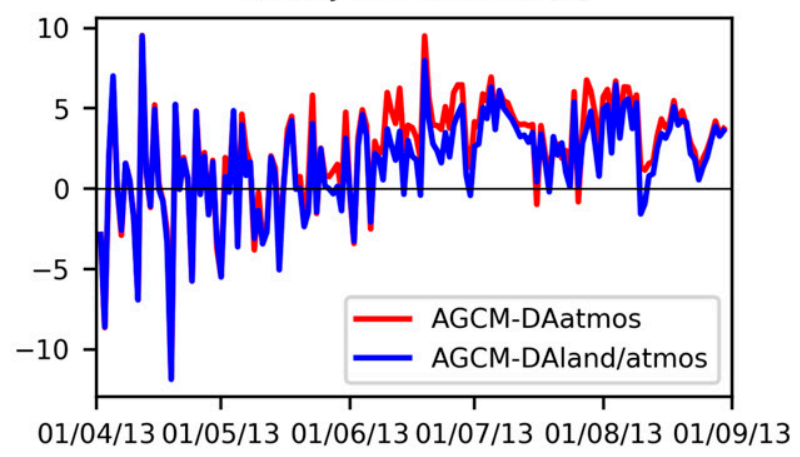

FIG. 13. As in Fig. 11, but at $\left(33.0^{\circ} \mathrm{N},-92.5^{\circ} \mathrm{E}\right)$ in the southeastern United States. which the assimilation wetted the surface and root-zone soil layers (Fig. 15a), increasing the latent heating, and slightly worsening the already cool $T_{\max }^{2 \mathrm{~m}}$ bias over the AGCM assimilation experiment period (Fig. 15d). Note that while the soil moisture in both layers was increased by a large amount relative to its temporal variability, the absolute change is rather small. For example, for the surface soil moisture the increase in soil moisture from the assimilation is less than $0.04 \mathrm{~m}^{3} \mathrm{~m}^{-3}$, or $2 \mathrm{~mm}$ across the 5 -cm layer.

The time series over the LSM experiment period in Fig. 16 shows that both ASCAT and SMOS were wetter than the model during the period of the AGCM assimilation experiments because of a general tendency to be wetter during the boreal summer. Also, in general, at this location the satellite soil moisture time series look unrealistic; they are noisy, ASCAT has unrealistic low spikes [possibly associated with known issues with the ASCAT retrieval algorithm in arid climates (Wagner et al. 2003)], and the SMOS ascending and descending time series often diverge. It will ultimately be very difficult for remote sensors to detect soil moisture changes with a reasonable signal to noise ratio in regions where the signal itself is so low (the range of the LSM-openloop surface soil moisture in Fig. 16 is close to $0.05 \mathrm{~m}^{3} \mathrm{~m}^{-3}$, just above the typical target accuracy of $0.04 \mathrm{~m}^{3} \mathrm{~m}^{-3}$ for satellite soil moisture).

Finally, while the model surface soil moisture was increased by the soil moisture assimilation in Fig. 15a, it remains lower than the assimilated observations (by comparison, in Figs. 11a and 13a the model surface soil moisture converged to close to the assimilated soil moisture time series by mid-May). Because of this lack of convergence, the soil moisture assimilation in the AGCM-DAland/atmos experiment continued to add small positive increments to the model soil moisture at each model analysis cycle. At this site, and across the Sahara, these small increments to the surface soil moisture (of 0.3-0.5 mm day ${ }^{-1}$ ) in AGCM-DAland/ atmos induced a small increase in the model surface soil moisture, and an increase in the latent heating (of $5-15 \mathrm{~W} \mathrm{~m}^{-2}$, equivalent to $0.2-0.5 \mathrm{~mm} \mathrm{day}^{-1}$ ), indicating that most of the water added to the soil moisture in a given assimilation cycle has then been immediately lost from the surface soil layer as evaporation (as would be expected in such an arid environment). Hence, the assimilation was unable to converge on the observed surface soil moisture time series, and continued to add positive increments.

\section{Discussion}

A weakly coupled land-atmosphere data assimilation system has been introduced, and then applied to 

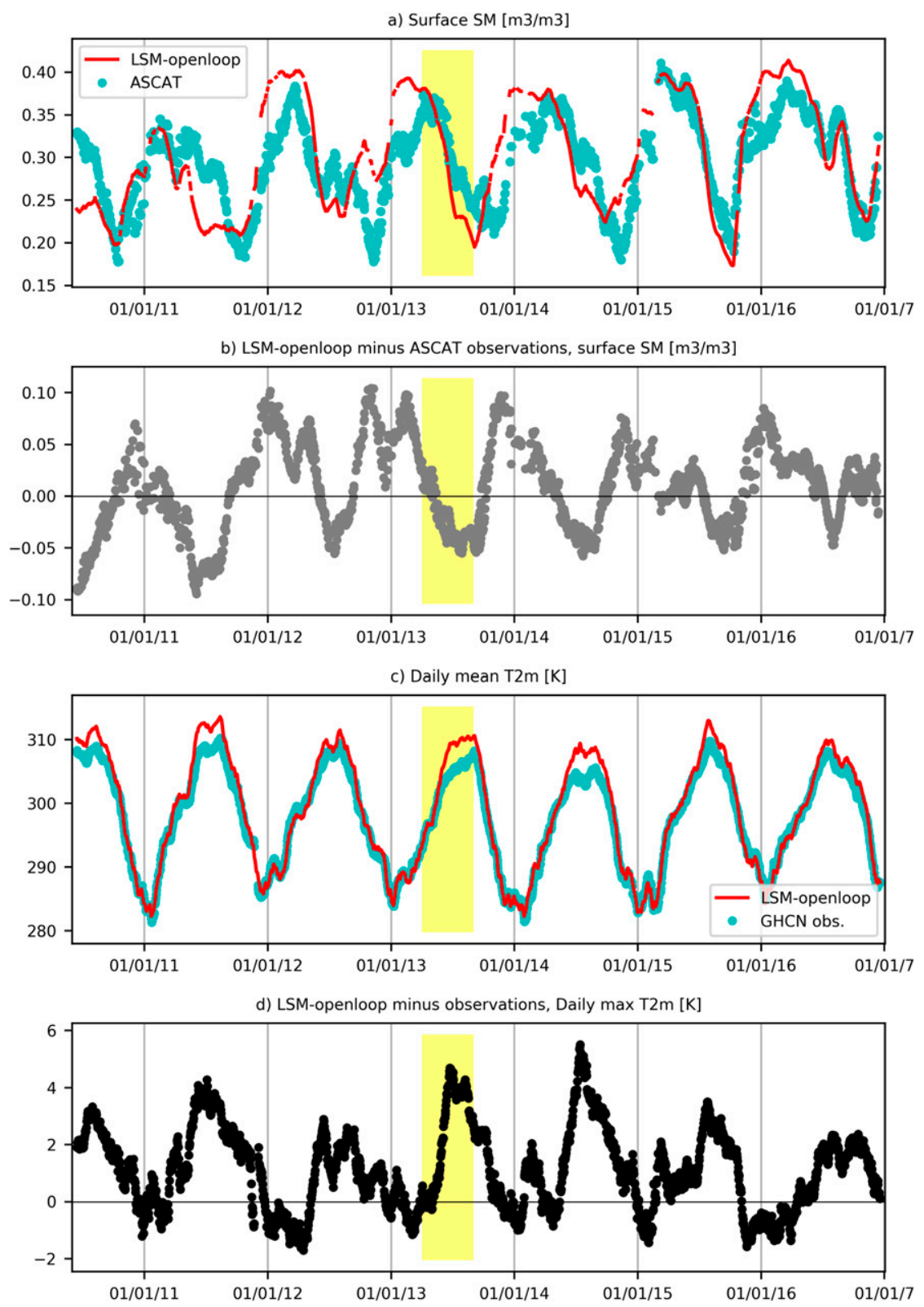

FIG. 14. As in Fig. 12 , but at $\left(33.0^{\circ} \mathrm{N},-92.5^{\circ} \mathrm{E}\right)$ in the southeastern United States.

assimilate satellite soil moisture from SMOS and ASCAT together with the standard suite of atmospheric observations used in the MERRA-2 reanalyses. The benefit of assimilating the satellite soil moisture was determined by comparison to a control experiment in which only the atmospheric observations were assimilated. These experiments were conducted over one (boreal) warm season, from April to August 2013. An additional pair of experiments was also performed, from June 2010 to December 2016, using an offline LSM, to confirm that assimilating the soil moisture observations improved the model soil moisture.
For the AGCM assimilation experiments, the benefit of the soil moisture assimilation was tested through comparison to independent observations of the land surface sensible and latent heat fluxes, daily maximum 2-m temperatures, and 2-m specific humidity. There were just 29 sites with flux data available from the FLUXNET2015 dataset during the experiment period, and at these sites the soil moisture assimilation significantly reduced the mean RMSE from 34.2 to $32.6 \mathrm{~W} \mathrm{~m}^{-2}$ for latent heating, and from 37.7 to $36.5 \mathrm{~W} \mathrm{~m}^{-2}$ for sensible heating. The 2-m station-based GHCN and HadISD datasets have much more extensive coverage, although both still only 
a) Surface SM $[\mathrm{m} 3 / \mathrm{m} 3]$

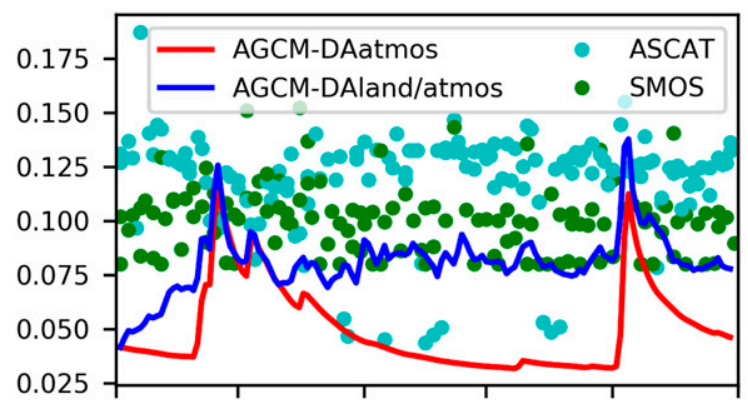

01/04/13 01/05/13 01/06/13 01/07/13 01/08/13 01/09/13

b) Root-zone SM $[\mathrm{m} 3 / \mathrm{m} 3]$

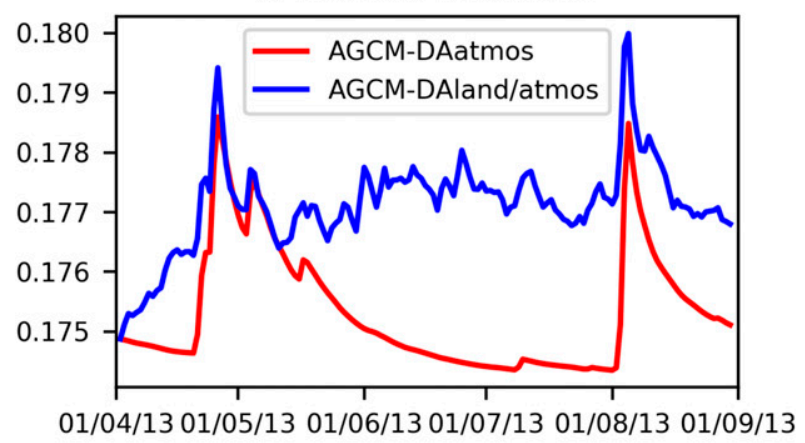

c) Latent heat $[\mathrm{W} / \mathrm{m} 2]$

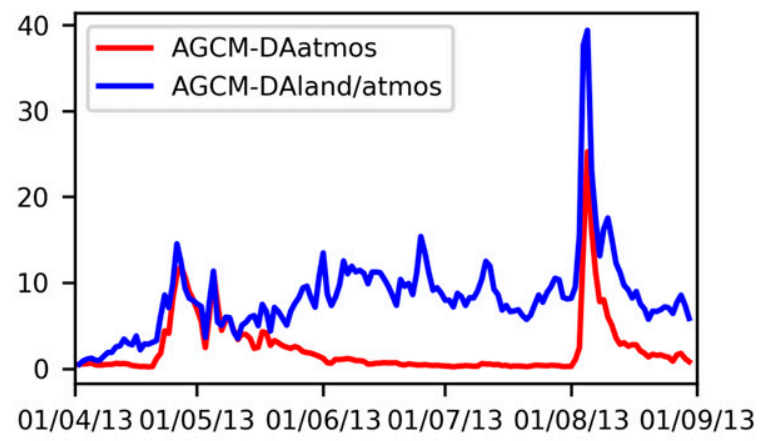

d) Daily max $\mathrm{T} 2 \mathrm{~m}$ bias $[\mathrm{K}]$

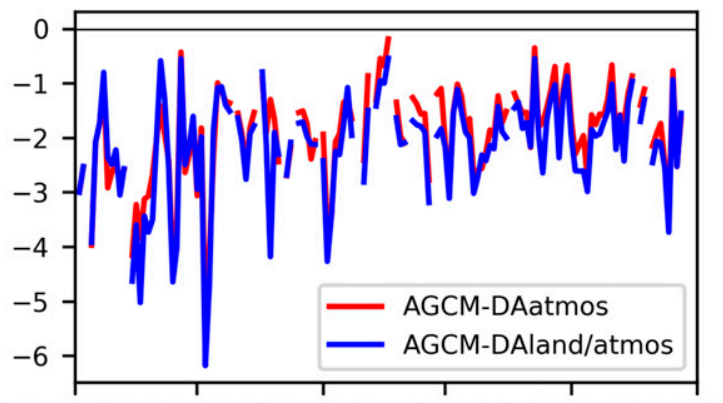

01/04/13 01/05/13 01/06/13 01/07/13 01/08/13 01/09/13

FIG. 15. As in Fig. 11, but at $\left(9.4^{\circ} \mathrm{N}, 24.5^{\circ} \mathrm{E}\right)$ in Algeria.

sample around $10 \%$ of the MERRA-2 grid cells (Fig. 3c). Compared to the GHCN $T_{\max }^{2 \mathrm{~m}}$ and HadISD $q^{2 \mathrm{~m}}$, the soil moisture assimilation slightly reduced the mean RMSE from 2.81 to $2.78 \mathrm{~K}$, and from 1.25 to $1.20 \mathrm{~g} \mathrm{~kg}^{-1}$, respectively.

While the mean improvements gained from the assimilation averaged across the FLUXNET2015, GHCN, and HadISD dataset locations are small, they are positive in each case. Additionally, there are regions where the local benefits are much larger. The most prominent example of this is the large region spanning from western Europe across southern Russia, in which the soil moisture assimilation improved the $T_{\max }^{2 \mathrm{~m}}$ RMSE by up $0.4 \mathrm{~K}$ (Fig. 9) and the $q^{2 \mathrm{~m}}$ RMSE by up to $0.5 \mathrm{~g} \mathrm{~kg}^{-1}$ (Fig. 10). Inspection of time series within this region showed that the reduced 2-m errors were due to the soil moisture assimilation identifying, and then correcting, an abnormal wet bias in the model soil moisture at the start of the experiment time period. Large global improvements in the 2-m temperature and humidity were not expected, since the atmospheric boundary layer is only sensitive to soil moisture within a certain soil moisture range. On a similar note, we also do not expect all of the boundary layer errors to be eliminated by improving the model soil moisture. For example in Fig. 13 the model $T_{\max }^{2 \mathrm{~m}}$ retains most of the bias from the AGCM-DAatmos experiment, even after the AGCMDAland/atmos experiment induced a relatively large change in the model soil moisture.

The intention of this study was to test the value of the soil moisture assimilation for future reanalysis, and a key detail of the experiments conducted here is that the assimilated soil moisture observations were bias corrected to match the model near-surface soil moisture using the maximum time period with available observations. With this approach, the assimilated observations still include any interannual soil moisture anomalies. This detail is important, as the model benefitted most from the soil moisture assimilation at time scales exceeding one month. First, the model root-zone soil moisture anomaly correlations were increased by assimilating the soil moisture observations only when the anomalies included interannual variability $\left(R_{\text {anom }}\right)$. If the anomalies instead accounted for only the current year subseasonal variability, then the root-zone anomaly correlations ( $\left.R_{\text {anom:subseas }}\right)$ were slightly decreased by the assimilation. This result suggests that the benefit to the root-zone soil moisture from the satellite soil moisture assimilation (as measured by $R_{\text {anom }}$ ) was in the simulation of events longer than one month. Second, even though the assimilation induced larger changes in the dayto-day variability of the latent heating and 2-m variables than in the monthly mean values (Fig. 7), comparison to independent evaluating datasets showed that the improved RMSE from the soil moisture 

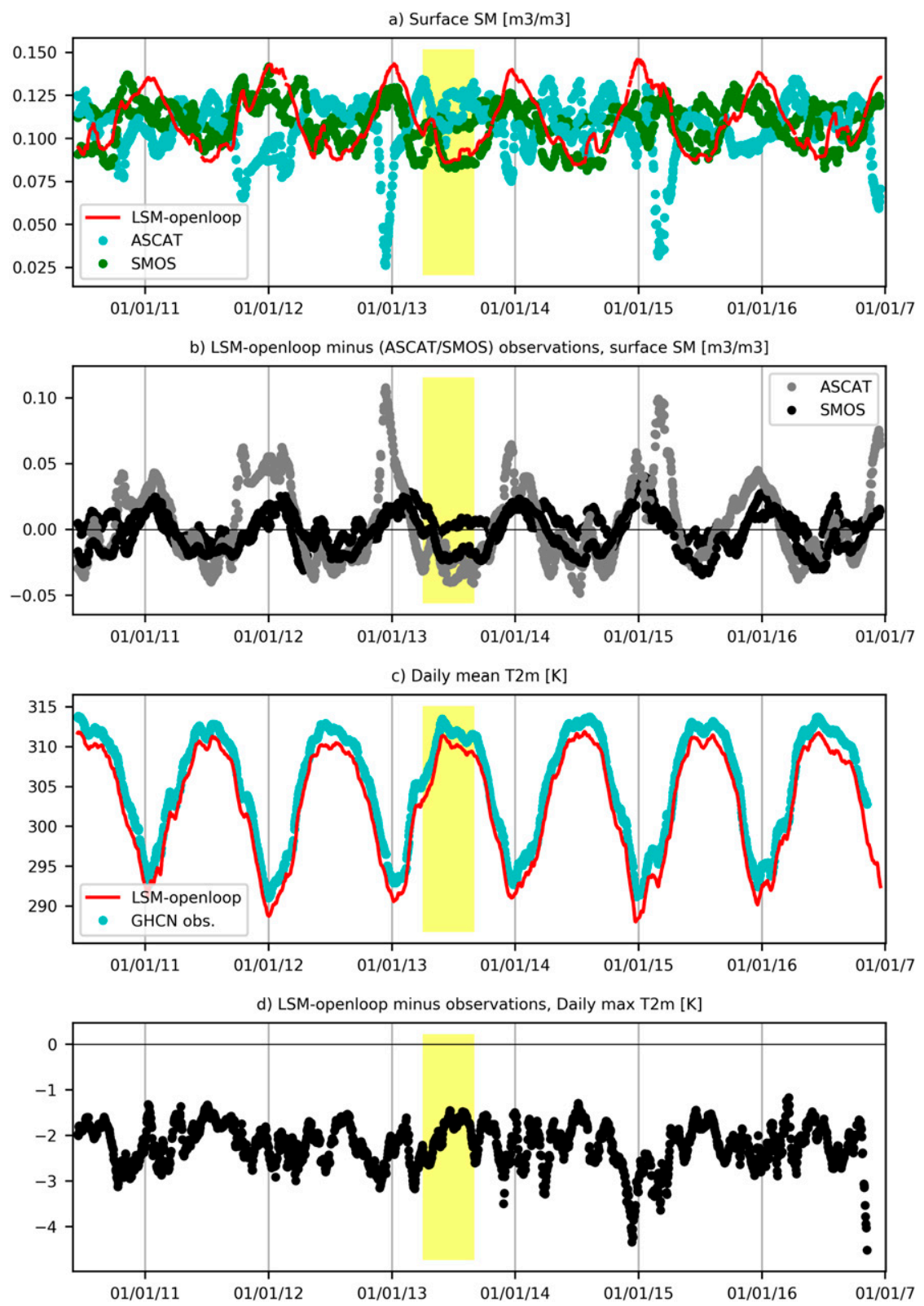

FIG. 16. As in Fig. 12 , but at $\left(9.4^{\circ} \mathrm{N}, 24.5^{\circ} \mathrm{E}\right)$ in Algeria.

assimilation was largely due to improved biases over monthly plus time scales, rather than due to improved ubRMSE.

Recall that in MERRA-2 and in the experiments presented in this study, the model-generated precipitation was corrected toward observations before entering the AGCM land surface. In line with the results of Liu et al. (2011), in this study the already high quality soil moisture obtained with the precipitation corrections was further improved (although by a small amount) by assimilating soil moisture observations. At the same time, some of the greatest improvements in the $T_{\max }^{2 \mathrm{~m}}$ and $q^{2 \mathrm{~m}}$ occurred north of $42.5^{\circ} \mathrm{N}$, where the model precipitation was only partially corrected toward the observations. It would not be unexpected that the greatest benefit from assimilating soil moisture occurs in regions where the observed precipitation is not fully weighted in the correction algorithm. Likewise, larger gains from soil moisture assimilation may also occur where the precipitation is fully corrected to observations, but the observed precipitation itself is less certain (e.g., over Africa, where the rain gauge network is relatively sparse). However, the evaluation of the assimilation output is also more 
difficult in these regions because of the same scarcity of ground-based data.

To maximize the potential benefit of assimilating soil moisture, the bias correction of the assimilated observations will require great care. An unresolved difficulty is that current bias correction strategies require an estimate of the model soil moisture climatology be available prior to commencing the reanalysis. Since precipitation is the main driver of soil moisture, in regions where the model precipitation will be corrected to observations, a reasonable estimate of the future reanalysis soil moisture climatology can be obtained by forcing the LSM in offline mode with reasonable atmospheric fields and the precipitation observations to be used in the reanalyses. However, where the precipitation observations will not be used (which is also where the soil moisture assimilation may offer the greatest benefit), an alternative bias correction approach will be needed. In this case, it would be sufficient to put the first year of each satellite data record aside for making an initial estimate of the bias correction (Draper and Reichle 2015), which could then be refined as more data become available.

Finally, as previously noted, the soil moisture assimilation degraded the model over the Sahara (and other arid regions), by persistently increasing the surface soil moisture. The added moisture was then evaporated to the atmosphere rather than being retained in the soil. Since in arid conditions the satellite soil moisture has a low signal-to-noise ratio and is unlikely to benefit the model, an additional quality control is recommended to screen out the soil moisture observations based on a minimum criterion for the local soil moisture time series standard deviation. Likewise, additional monitoring is recommended to identify and address serially correlated observation-minus-forecast residuals or assimilation increments, which indicate that the assimilation is unable to sustainably correct the model toward the observations. Serially correlated increments can result in a relatively large moisture increment being gradually added or subtracted over time. While for assimilation into an offline LSM, the impact of this issue would be locally restricted (since LSMs typically do not include lateral flow), for assimilation into a full AGCM, the addition or subtraction of a large water volume could potentially impact the global circulation, as likely occurred in response to the relatively large increase in latent heating over the Sahara in this study.

\section{Conclusions and recommendations}

The experiments presented here demonstrated that assimilating satellite soil moisture retrievals into a global atmospheric reanalysis can improve the model representation of soil moisture, leading to improved latent and sensible heating, and hence improved daily maximum temperature and specific humidity in the boundary layer. While the globally averaged improvements were small, the model benefits were more pronounced locally. Additionally, while the model changes in latent heat, $T_{\max }^{2 \mathrm{~m}}$, and $q^{2 \mathrm{~m}}$ induced by the assimilation show greater variability at the day-to-day time scale, the model improvements (based on comparison to independent observations) are dominated by improvements at monthly and longer time scales. An obvious extension to this study would be to use the improved soil moisture estimates from the weakly coupled assimilation system to initialize short-and medium-range weather forecasts. It if left to future work to determine whether this can improve the forecast skill.

Evaluation of gridded soil moisture, such as from an AGCM, is extremely difficult because of the representativity differences between in situ and modeled soil moisture, and the limited global coverage of in situ networks (demonstrated in Fig. 3a). It is quite possible that evaluations based on in situ soil moisture observations, such as was presented in section $3 \mathrm{a}$, underestimate the true impact of assimilating soil moisture. By comparison, the available network of station-based 2-m observations is much more globally extensive (although still far from global; Figs. 3c,d), and representativity differences between the modeled and observed 2-m temperature and humidity are also much smaller. The conclusion from this study that the satellite soil moisture assimilation improved the overall fit between the modeled and observed $T_{\max }^{2 \mathrm{~m}}$ and $q^{2 \mathrm{~m}}$ then provides an important independent confirmation that soil moisture assimilation can improve modeled soil moisture.

Looking ahead, we recommend that satellite soil moisture information be assimilated into future atmospheric reanalyses, including the follow-on reanalyses from MERRA-2. The GEOS 3D-Var atmospheric data assimilation system used here was updated to a Hybrid 3D-Var scheme in May 2016, and then to a 4D-Var scheme in January 2017 (Todling and El Akkraoui 2018), and the coupled land-atmosphere data assimilation system needs to be similarly updated. This also presents an opportunity to improve the land EnKF by better integrating the land ensemble used in the land update with the AGCM ensemble used in the Hybrid 4D-Var data assimilation.

Acknowledgments. This work was supported by the NASA Terrestrial Hydrology program (NNX15AB52G), and the NASA Modeling, Analysis and Prediction program. Computational resources were provided by the 
TABLE A1. ISMN contributing networks used in this study.

\begin{tabular}{ll}
\hline \multicolumn{1}{c}{ Network } & \multicolumn{1}{c}{ Citation or website } \\
\hline COSMOS & Zreda et al. (2012) \\
DAHRA & Tagesson et al. (2015) \\
HOBE & Bircher et al. (2012) \\
hEMEDHUS & htt/campus.usal.es/ hidrus/ \\
(accessed 5 Feb 2018) & https://www.wcc.nrcs.usda.gov/scan/ \\
SCAN & (accessed 5 Feb 2018) \\
SMOSMANIA & Albergel et al. (2008) \\
SNOTEL & (accessed 5 Feb 2018) \\
TERENO & Zacharias et al. (2011) \\
USCRN & Bell et al. (2013) \\
WSMN & http://www.aber.ac.uk/wsmn \\
& (accessed 5 Feb 2018) \\
\hline
\end{tabular}

NASA High-End Computing program through the NASA Center for Climate Simulation. We are also grateful to the Vienna University of Technology for providing the ASCAT data, the European Space Agency for the SMOS data, Gabrielle De Lannoy at KU Leuven for processing the SMOS data, and the NOAA National Climatic Data Center for the GHCN data. This work used eddy covariance data acquired and shared by the FLUXNET community, including these networks: AmeriFlux, AfriFlux, AsiaFlux, CarboAfrica, CarboEuropeIP, CarboItaly, CarboMont, ChinaFlux, Fluxnet-Canada, GreenGrass, ICOS, KoFlux, LBA, NECC, OzFlux-TERN, TCOS-Siberia, and USCCC. The FLUXNET eddy covariance data processing and harmonization was carried out by the European Fluxes Database Cluster, AmeriFlux Management Project, and Fluxdata project of FLUXNET, with the support of CDIAC and ICOS Ecosystem Thematic Center, and the OzFlux, ChinaFlux and AsiaFlux offices (see the appendix for the sites used). This work used soil moisture observations hosted by the ISMN, and contributed by the networks listed in the appendix.

\section{APPENDIX}

\section{Preparation of Observation Data Used for Evaluation}

To evaluate the model soil moisture, hourly ISMN observations were downloaded, retaining only nonzero data that are classified as "good" (Dorigo et al. 2013).

TABLE A2. FLUXNET2015 sites used in this study.

\begin{tabular}{|c|c|c|c|}
\hline FLUXNET-ID & {$\left[\right.$ lat $\left({ }^{\circ} \mathrm{N}\right)$, lon $\left.\left({ }^{\circ} \mathrm{E}\right)\right]$} & Data years used & Data DOI \\
\hline AU-ASM & $(-22.2830,133.2490)$ & 2013 & 10.18140/FLX/1440194 \\
\hline AU-Cpr & $(-34.0021,140.5891)$ & 2013 & 10.18140/FLX/1440195 \\
\hline AU-Cum & $(-33.6152,150.7236)$ & 2013 & 10.18140/FLX/1440196 \\
\hline AU-DaP & $(-14.0633,131.3181)$ & 2013 & 10.18140/FLX/1440123 \\
\hline AU-Dry & $(-15.2588,132.3706)$ & 2013 & 10.18140/FLX/1440197 \\
\hline AU-Emr & $(-23.8587,148.4746)$ & 2013 & 10.18140/FLX/1440198 \\
\hline AU-GWW & $(-30.1913,120.6541)$ & 2013 & 10.18140/FLX/1440200 \\
\hline AU-RDF & $(-14.5636,132.4776)$ & 2013 & 10.18140/FLX/1440201 \\
\hline AU-Stp & $(-17.1507,133.3502)$ & 2013 & 10.18140/FLX/1440204 \\
\hline AU-Whr & $(-36.6732,145.0294)$ & 2013 & 10.18140/FLX/1440206 \\
\hline AU-Ync & $(-34.9893,146.2907)$ & 2013 & 10.18140/FLX/1440208 \\
\hline BE-Bra & $(51.3076,4.5198)$ & 2013 & 10.18140/FLX/1440128 \\
\hline BE-Lon & $(50.5516,4.7461)$ & 2013 & 10.18140/FLX/1440129 \\
\hline BE-Vie & $(50.3050,5.9981)$ & 2013 & 10.18140/FLX/1440130 \\
\hline CZ-wet & $(49.0247,14.7704)$ & 2013 & 10.18140/FLX/1440145 \\
\hline DE-Geb & $(51.1001,10.9143)$ & 2013 & 10.18140/FLX/1440146 \\
\hline DE-RuR & $(50.6219,6.3041)$ & 2013 & 10.18140/FLX/1440215 \\
\hline DE-Tha & $(50.9624,13.5652)$ & 2013 & $10.18140 / \mathrm{FLX} / 1440152$ \\
\hline NL-Loo & $(52.1666,5.7436)$ & 2013 & 10.18140/FLX/1440178 \\
\hline RU-Cok & $(70.8291,147.4943)$ & 2013 & 10.18140/FLX/1440182 \\
\hline RU-Fyo & $(56.4615,32.9221)$ & 2013 & 10.18140/FLX/1440183 \\
\hline U.S.-MMS & $(39.3232,-86.4131)$ & 2013 & $10.18140 / \mathrm{FLX} / 1440083$ \\
\hline U.S.-Ne3 & $(41.1797,-96.4397)$ & 2013 & 10.18140/FLX/1440086 \\
\hline U.S.-Prr & $(65.1237,-147.4876)$ & 2013 & 10.18140/FLX/1440113 \\
\hline U.S.-SRG & $(31.7894,-110.8277)$ & 2013 & 10.18140/FLX/1440114 \\
\hline U.S.-Tw3 & $(38.1159,-121.6467)$ & 2013 & 10.18140/FLX/1440110 \\
\hline U.S.-Var & $(38.4133,-120.9507)$ & 2013 & 10.18140/FLX/1440094 \\
\hline U.S.-WCr & $(45.8059,-90.0799)$ & 2013 & 10.18140/FLX/1440095 \\
\hline U.S.-Wkg & $(31.7365,-109.9419)$ & 2013 & 10.18140/FLX/1440096 \\
\hline
\end{tabular}


These hourly observations were averaged up to daily time series, and all time series with less than 1460 data days within the June 2010 to December 2016 LSM experiment period were discarded. The measurement depths that best represent the surface and root-zone soil moisture were then selected. For the surface soil moisture, we chose the time series within each MERRA-2 grid cell that is closest to the surface, but no deeper than $10 \mathrm{~cm}$. For the root-zone soil moisture, we chose the time series closest to $34-\mathrm{cm}$ depth, and between 10 and $60 \mathrm{~cm}$ deep. In instances where there were multiple sensors at the same depth within a grid cell, the time series with the highest anomaly correlation with the LSM-openloop soil moisture was selected (assuming that this minimizes the representativity differences between the chosen in situ and modeled soil moisture). Finally, all time series at locations with no ASCAT or SMOS soil moisture observations, or where the anomaly correlation with LSM-openloop was below 0.2 were also discarded. The latter threshold serves as additional quality control for ISMN soil moisture measurements that are subject to otherwise undetected measurement errors or are not representative of the gridcell-scale model estimates. Table A1 lists the contributing ISMN networks used, together with the relevant citations.

To evaluate the model latent and sensible heat fluxes, the FLUXNET2015 Tier 1 hourly data were downloaded, and the energy-balance closure-corrected hourly latent and sensible heat fluxes were averaged up to daily time series, for all days with less than $10 \%$ gap-filled data. All sites with at least 100 data days during the (153 day) AGCM assimilation experiment period were then retained. Where there was more than one time series within a model grid cell, only the site with the lowest RMSE compared to the AGCM-DAatmos experiment was retained. Finally, sites at which there were no ASCAT or SMOS observations available for assimilation were discarded. The final list of stations used, together with the relevant citations, are shown in Table A2.

To evaluate the model $T_{\max }^{2 \mathrm{~m}}$, version 3.24 of the global GHCN $T_{\max }^{2 \mathrm{~m}}$ observations were downloaded, and all data failing the GHCN quality assurance checks were discarded. We then created a daily gridded dataset on the MERRA-2 output grid by averaging all available observations within each model grid cell on each day. Grid cells with less than 100 data days were then discarded. For the $q^{2 \mathrm{~m}}$, version 3.0.0.2018f, of the hourly station-based HadISD data were downloaded, and daily values were estimated for all stations on each day with at least three observations. The daily time series were then processed onto the model grid cells using the same process as for the GHCN $T_{\max }^{2 \mathrm{~m}}$ data. Daily estimates of the model $q^{2 \mathrm{~m}}$ were specially produced for comparison to HadISD using only the hours at which the HadISD observations were available.

\section{REFERENCES}

Albergel, C., and Coauthors, 2008: From near-surface to root-zone soil moisture using an exponential filter: An assessment of the method based on in-situ observations and model simulations. Hydrol. Earth Syst. Sci., 12, 1323-1337, https://doi.org/10.5194/ hess-12-1323-2008.

Bélair, S., L.-P. Crevier, J. Mailhot, B. Bilodeau, and Y. Delage, 2003: Operational implementation of the ISBA land surface scheme in the Canadian regional weather forecast model. Part I: Warm season results. J. Hydrometeor., 4, 352-370, https:// doi.org/10.1175/1525-7541(2003)4<352:OIOTIL >2.0.CO;2.

Bell, J., and Coauthors, 2013: U.S. Climate Reference Network soil moisture and temperature observations. J. Hydrometeor., 14, 977-988, https://doi.org/10.1175/JHM-D-12-0146.1.

Benjamin, S., and Coauthors, 2016: A North American hourly assimilation and model forecast cycle: The Rapid Refresh. Mon. Wea. Rev., 144, 1669-1694, https://doi.org/10.1175/MWR-D-15-0242.1.

Betts, A., 2009: Land-surface-atmosphere coupling in observations and models. J. Adv. Model. Earth Syst., 1 (3), https://doi.org/ 10.3894/JAMES.2009.1.4.

Bircher, S., N. Skou, K. Jensen, J. Walker, and L. Rasmussen, 2012: A soil moisture and temperature network for SMOS validation in western Denmark. Hydrol. Earth Syst. Sci., 16, 14451463, https://doi.org/10.5194/hess-16-1445-2012.

Bloom, S., L. Takacs, A. da Silva, and D. Ledvina, 1996: Data assimilation using incremental analysis updates. Mon. Wea. Rev., 124, 1256-1271, https://doi.org/10.1175/1520-0493(1996)124<1256: DAUIAU $>2.0 . \mathrm{CO} ; 2$.

Candy, B., R. Saunders, D. Ghent, and C. Bulgin, 2017: The impact of satellite-derived land surface temperatures on numerical weather prediction analyses and forecasts. J. Geophys. Res. Atmos., 122, 9783-9802, https://doi.org/10.1002/2016JD026417.

Carrera, M., S. Bélair, and B. Bilodeau, 2015: The Canadian land data assimilation system (CaLDAS): Description and synthetic evaluation study. J. Hydrometeor., 16, 1293-1314, https:// doi.org/10.1175/JHM-D-14-0089.1.

_- B. Bilodeau, S. Bélair, M. Abrahamowicz, A. Russell, and X. Wang, 2019: Assimilation of passive L-band microwave brightness temperatures in the Canadian land data assimilation system: Impacts on short-range warm season numerical weather prediction. J. Hydrometeor., https://doi.org/ 10.1175/JHM-D-18-0133.1, in press.

De Lannoy, G., and R. Reichle, 2016: Assimilation of SMOS brightness temperatures or soil moisture retrievals into a land surface model. Hydrol. Earth Syst. Sci., 20, 4895-4911, https:// doi.org/10.5194/hess-20-4895-2016.

de Rosnay, P., M. Drusch, D. Vasiljevic, G. Balsamo, C. Albergel, and L. Isaksen, 2013: A simplified extended Kalman filter for the global operational soil moisture analysis at ECMWF. Quart. J. Roy. Meteor. Soc., 139, 1199-1213, https://doi.org/ 10.1002/qj.2023.

Dharssi, I., K. Bovis, B. Macpherson, and C. Jones, 2011: Operational assimilation of ASCAT surface soil wetness at the Met Office. Hydrol. Earth Syst. Sci., 15, 2729-2746, https://doi.org/ 10.5194/hess-15-2729-2011.

Dirmeyer, P., and S. Halder, 2016: Sensitivity of numerical weather forecasts to initial soil moisture variations in CFSv2. Wea. Forecasting, 31, 1973-1983, https://doi.org/10.1175/WAF-D-16-0049.1. 
Dorigo, W., and Coauthors, 2011: The International soil moisture network: A data hosting facility for global in situ soil moisture measurements. Hydrol. Earth Syst. Sci., 15, 1675-1698, https:// doi.org/10.5194/hess-15-1675-2011.

__ , and Coauthors, 2013: Global automated quality control of in situ soil moisture data from the International Soil Moisture Network. Vadose Zone J., 12, vzj2012.0097, https://doi.org/ 10.2136/vzj2012.0097.

Draper, C., and R. Reichle, 2015: The impact of near-surface soil moisture assimilation at subseasonal, seasonal, and interannual timescales. Hydrol. Earth Syst. Sci., 19, 4831-4844, https://doi.org/10.5194/hess-19-4831-2015.

——, and — , 2018: Observation error specification for nearsurface soil moisture assimilation: Does it matter? 32nd Conf. on Hydrology, Austin, TX, Amer. Meteor. Soc., 877, https://ams.confex.com/ams/98Annual/webprogram/ Paper333179.html.

__ J.-F. Mahfouf, and J. Walker, 2011: Root-zone soil moisture from the assimilation of screen-level variables and remotely sensed soil moisture. J. Geophys. Res., 116, D02127, https:// doi.org/10.1029/2010JD013829.

_ _, R. Reichle, G. De Lannoy, and Q. Liu, 2012: Assimilation of passive and active microwave soil moisture retrievals. Geophys. Res. Lett., 39, L04401, https://doi.org/10.1029/2011GL050655.

,-- , R. de Jeu, V. Naeimi, R. Parinussa, and W. Wagner, 2013: Estimating root mean square errors in remotely sensed soil moisture over continental scale domains. Remote Sens. Environ., 137, 288-298, https://doi.org/10.1016/j.rse.2013.06.013.

,-- , and R. Koster, 2018: Assessment of MERRA-2 land surface energy flux estimates. J. Climate, 31, 671-691, https:// doi.org/10.1175/JCLI-D-17-0121.1.

Drusch, M., and P. Viterbo, 2007: Assimilation of screen-level variables in ECMWF's Integrated Forecast System: A study on the impact on the forecast quality and analyzed soil moisture. Mon. Wea. Rev., 135, 300-314, https://doi.org/10.1175/ MWR3309.1.

Dunn, R., K. Willett, D. Parker, and L. Mitchell, 2016: Expanding HadISD: Quality-controlled, sub-daily station data from 1931. Geosci. Instrum. Methods Data Syst., 5, 473-491, https:// doi.org/10.5194/gi-5-473-2016.

Entin, J., A. Robock, K. Vinnikov, S. Hollinger, S. Liu, and A. Namkhai, 2000: Temporal and spatial scales of observed soil moisture variations in the extratropics. J. Geophys. Res., 105, 11 865-11 877, https://doi.org/10.1029/2000JD900051.

Fairbairn, D., A. Barbu, J.-F. Mahfouf, J.-C. Calvet, and E. Gelati, 2015: Comparing the ensemble and extended Kalman filters for in situ soil moisture assimilation with contrasting conditions. Hydrol. Earth Syst. Sci., 19, 4811-4830, https://doi.org/ 10.5194/hess-19-4811-2015.

Fluxnet, 2015: FLUXNET2015 dataset. Fluxdata, U.S. Department of Energy, Office of Science, accessed 9 August 2016, http://fluxnet.fluxdata.org/data/fluxnet2015-dataset/.

Gelaro, R., and Coauthors, 2017: The Modern-Era Retrospective Analysis for Research and Applications, version 2 (MERRA-2). J. Climate, 30, 5419-5454, https://doi.org/10.1175/JCLI-D16-0758.1.

Hersbach, H., and D. Dee, 2016: ERA5 reanalysis is in production. ECMWF Newsletter, No. 147, ECMWF, Reading, United Kingdom, 7, https://www.ecmwf.int/en/newsletter/147/news/ era5-reanalysis-production.

Hess, H., 2001: Assimilation of screen-level observations by variational soil moisture analysis. Meteor. Atmos. Phys., 77, 145154, https://doi.org/10.1007/s007030170023.
Kleist, D., D. Parrish, J. Derber, R. Treadon, W.-S. Wu, and S. Lord, 2009: Introduction of the GSI into the NCEP global data assimilation system. Wea. Forecasting, 24, 1691-1705, https://doi.org/10.1175/2009WAF2222201.1.

Koster, R., M. Suarez, A. Ducharne, M. Stieglitz, and P. Kumar, 2000: A catchment-based approach to modeling land surface processes in a general circulation model: 1. Model structure. J. Geophys. Res., 105, 24 809-24 822, https://doi.org/10.1029/2000JD900327.

_- Z. Z. Guo, R. Yang, P. Dirmeyer, K. Mitchell, and M. Puma, 2009: On the nature of soil moisture in land surface models. J. Climate, 22, 4322-4335, https://doi.org/10.1175/ 2009JCLI2832.1.

—_ and Coauthors, 2010: Contribution of land surface initialization to subseasonal forecast skill: First results from a multi-model experiment. Geophys. Res. Lett., 37, L02402, https://doi.org/10.1029/2009GL041677.

Liu, Q., and Coauthors, 2011: The contributions of precipitation and soil moisture observations to the skill of soil moisture estimates in a land data assimilation system. J. Hydrometeor., 12, 750-765, https://doi.org/10.1175/JHM-D-10-05000.1.

Mahfouf, J.-F., 1991: Analysis of soil moisture from near-surface parameters: A feasibility study. J. Appl. Meteor., 30, 1534-1547, https://doi.org/10.1175/1520-0450(1991)030<1534:AOSMFN > 2.0.CO;2.

Menne, M., I. Durre, R. Vose, B. Gleason, and T. Houston, 2012a: An overview of the global historical climatology networkdaily database. J. Atmos. Oceanic Technol., 29, 897-910, https://doi.org/10.1175/JTECH-D-11-00103.1.

—, and Coauthors, 2012b: Global Historical Climatology Network-Daily (GHCN-Daily), version 3.24. NOAA National Climatic Data Center, accessed 10 April 2018, https:// doi.org/10.7289/V5D21VHZ.

Milbrandt, J., S. Bélair, M. Faucher, M. Vallee, M. Carrera, and A. Glazer, 2016: The Pan-Canadian High Resolution $(2.5 \mathrm{~km})$ Deterministic Prediction System. Wea. Forecasting, 31, 17911816, https://doi.org/10.1175/WAF-D-16-0035.1.

Molod, A., L. Takacs, M. Suarez, and J. Bacmeister, 2015: Development of the GEOS-5 atmospheric general circulation model: Evolution from MERRA to MERRA-2. Geosci. Model Dev., 8, 1339-1356, https://doi.org/10.5194/gmd-8-1339-2015.

Muñoz Sabater, J., L. Jarlan, J.-C. Calvet, F. Bouyssel, and P. De Rosnay, 2007: From near-surface to root-zone soil moisture using different assimilation techniques. J. Hydrometeor., $\mathbf{8}$, 194-206, https://doi.org/10.1175/JHM571.1.

Naeimi, V., K. Scipal, Z. Bartalis, S. Hasenauer, and W. Wagner, 2009: An improved soil moisture retrieval algorithm for ERS and METOP scatterometer observations. IEEE Trans. Geosci. Remote Sens., 47, 1999-2013, https://doi.org/10.1109/ TGRS.2008.2011617.

Oliva, R., E. Daganzo, Y. Kerr, S. Mecklenburg, S. Nieto, P. Richaume, and C. Gruhier, 2012: SMOS radio frequency interference scenario: Status and actions taken to improve the RFI environment in the $1400-1427-\mathrm{MHz}$ passive band. IEEE Trans. Geosci. Remote Sens., 50, 1427-1439, https://doi.org/ 10.1109/TGRS.2012.2182775.

Peters-Lidard, C., S. Kumar, D. Mocko, and Y. Tian, 2011: Estimating evapotranspiration with land data assimilation systems. Hydrol. Processes, 25, 3979-3992, https://doi.org/10.1002/hyp.8387.

Reichle, R., and R. Koster, 2004: Bias reduction in short records of satellite soil moisture. Geophy. Res. Lett., 31, L19501, https:// doi.org/10.1029/2004GL020938.

-, J. Walker, R. Koster, and P. Houser, 2002: Extended versus ensemble Kalman filtering for land data assimilation. 
J. Hydrometeor., 3, 728-740, https://doi.org/10.1175/15257541(2002)003<0728:EVEKFF>2.0.CO;2.

- R. Koster, J. Dong, and A. Berg, 2004: Global soil moisture from satellite observations, land surface models, and ground data: Implications for data assimilation. J. Hydrometeor., 5, 430-442, https://doi.org/10.1175/1525-7541(2004)005<0430: GSMFSO $>2.0 . \mathrm{CO} ; 2$.

—, C. Draper, Q. Liu, M. Girotto, S. Mahanama, R. Koster, and G. D. Lannoy, 2017a: Assessment of MERRA-2 land surface hydrology estimates. J. Climate, 30, 2937-2960, https://doi.org/ 10.1175/JCLI-D-16-0720.1.

— , Q. Liu, R. Koster, C. Draper, S. Mahanama, and G. Partyka, 2017b: Land surface precipitation in MERRA-2. J. Climate, 30, 1643-1664, https://doi.org/10.1175/JCLI-D-16-0570.1.

— 4 surface and root-zone soil moisture product using assimilation diagnostics. J. Hydrometeor., 18, 3217-3237, https:// doi.org/10.1175/JHM-D-17-0130.1.

Rienecker, M., and Coauthors, 2008: The GEOS-5 data assimilation system-Documentation of Versions 5.0.1, 5.1.0, and 5.2.0. Tech. Rep. Series on Global Modeling and Data Assimilation, NASA/TM-2008-104606, Vol. 27, 118 pp.

Rodriguez, E., J. Navascues, and S. Ayuso, and S. Järvenoja, 2003: Analysis of surface variables and parameterisation of surface processes in HIRLAM. Part 1: Approach and verification by parallel runs. HIRLAM Tech. Rep. 59, Norrköping, Sweden, $52 \mathrm{pp}$.

Saha, S., and Coauthors, 2010: The NCEP Climate Forecast System Reanalysis. Bull. Amer. Meteor. Soc., 91, 1015-1058, https:// doi.org/10.1175/2010BAMS3001.1.

— version 2. J. Climate, 27, 2185-2208, https://doi.org/10.1175/ JCLI-D-12-00823.1.

Smith, A., N. Lott, and R. Vose, 2011: The integrated surface database: Recent developments and partnerships. Bull. Amer. Meteor. Soc., 92, 704-708, https://doi.org/10.1175/ 2011BAMS3015.1.

Tagesson, T., and Coauthors, 2015: Ecosystem properties of semiarid savanna grassland in West Africa and its relationship with environmental variability. Global Change Biol., 21, 250264, https://doi.org/10.1111/gcb.12734.

Todling, R., and A. El Akkraoui, 2018: The GMAO hybrid ensemble-variational atmospheric data assimilation system: Version 2.0. NASA Tech. Rep. Series on Global Modeling and Data Assimilation, NASA/TM-2018-104606, Vol. 50, 184 pp.

USGS, 2000: Global land cover characteristics data base, version 2.0. Accessed 14 May 2019, https://www.usgs.gov/media/images/ global-land-cover-characteristics-data-base-version-20.

van den Hurk, B., F. Doblas-Reyes, G. Balsamo, R. Koster, S. Seneviratne, and H. Camargo, 2012: Soil moisture effects on seasonal temperature and precipitation forecast scores in Europe. Climate Dyn., 38, 349-362, https://doi.org/10.1007/ s00382-010-0956-2.

Vinnikov, K., A. Robock, N. Speranskaya, and C. Sclosser, 1996: Scales of temporal and spatial variability of midlatitude soil moisture. J. Geophys. Res., 101, 7163-7174, https://doi.org/ 10.1029/95JD02753.

Wagner, W., G. Lemoine, and H. Rott, 1999: A method for estimating soil moisture from ERS scatterometer and soil data. Remote Sens. Environ., 70, 191-207, https://doi.org/10.1016/ S0034-4257(99)00036-X.

- K. Kcipal, C. Pathe, D. Gerten, W. Lucht, and B. Rudolf, 2003: Evaluation of the agreement between the first global remotely sensed soil moisture data with model and precipitation data. J. Geophys. Res., 108, 4611, https://doi.org/ 10.1029/2003JD003663.

Wu, W.-S., R. J. Purser, and D. Parrish, 2002: Three-dimensional variational analysis with spatially inhomogeneous covariances. Mon. Wea. Rev., 130, 2905-2916, https://doi.org/ 10.1175/1520-0493(2002)130<2905:TDVAWS > 2.0.CO;2.

Zacharias, S., and Coauthors, 2011: A network of terrestrial environmental observatories in Germany. Vadose Zone J., 10, 955973, https://doi.org/10.2136/vzj2010.0139.

Zreda, M., W. Shuttleworth, X. Zeng, C. Zweck, D. Desilets, T. Franz, and R. Rosolem, 2012: COSMOS: The Cosmic-ray Soil Moisture Observing System. Hydrol. Earth Syst. Sci., 16, 4079-4099, https://doi.org/10.5194/hess-16-4079-2012. 